\title{
Influência dos Aspectos Socioculturais em Um Modelo de Maturidade para Gestão do Conhecimento
}

\section{Influence of Sociocultural Aspects on a Knowledge Management Maturity Model}

\author{
Yoji Massago $^{1}$, Douglas Rorie Tanno ${ }^{1}$, Renato Balancieri ${ }^{2}$, Gislaine Camila \\ Lapasini Leal ${ }^{3}$, Edwin Vladimir Cardoza Galdamez ${ }^{3}$, Elisa Huzita ${ }^{1}$
}

${ }^{1}$ Departamento de Informática - Universidade Estadual de Maringá (UEM) - Maringá PR - Brasil

${ }^{2}$ Universidade Estadual do Paraná (UNESPAR) - Apucarana, PR - Brasil

${ }^{3}$ Departamento de Engenharia de Produção

Universidade Estadual de Maringá (UEM) - Maringá, PR - Brasil

\{yojimassago, douglas.tanno\}@gmail.com.br,

renato.balancieri@unespar.edu.br, \{gclleal, evcgaldamez\}@uem.br, elisa.h.m.huzita@gmail.com

Abstract. Nowadays, the use of Knowledge Management in companies that adopt the Distributed Software Development (DSD) approach is fundamental. The development and/or maturation of this management can be mapped on Knowledge Management Maturity Models (KMMM). The purpose of this paper is to determine the influence of sociocultural aspects from DSD, over a KMMM. To this end, a KMMM was chosen to be considered as a basis, in this case the KNM (Knowledge Navigator Model), and a study was carried out to identify the influence of the sociocultural aspects present in DDS. In the analysis of the data, it sought the support present in the definition of QFD (Quality Function Deployment). In this study, the participants consider that sociocultural aspects have influence on KNM maturity model. Also, it is pointed the influence level (strong, moderate, weak and nonexistent) of the sociocultural aspects identified.

Keywords. Distributed Software Development; Sociocultural Aspects; Knowledge Management; Knowledge Management Maturity Models.

Resumo. Atualmente, é fundamental a utilização da Gestão do Conhecimento em empresas que utilizam Desenvolvimento Distribuído de Software (DDS). A evolução elou amadurecimento desta gestão podem ser mapeadas em Modelos de Maturidade para Gestão do Conhecimento (KMMM). Este artigo tem como objetivo verificar a influência dos aspectos socioculturais, presentes em DDS, sobre um KMMM. Para tal, procedeu-se a escolha de um KMMM, neste caso o KNM (Knowledge Navigator Model) e executou-se um estudo para identificar a influência dos aspectos socioculturais presentes no DDS. Na análise dos dados, buscou-se o suporte presente na definição do QFD

Cite as: Massago, Y., Tanno, D. R., Balancieri, R., Leal, G. C. L., Galdamez, E. V. C. \& Huzita, E.. (2019). Influence of Sociocultural Aspects on a Knowledge Management Maturity Model (Influência dos Aspectos Socioculturais em Um Modelo de Maturidade para Gestão do Conhecimento). iSys: Revista Brasileira de Sistemas de Informação (Brazilian Journal of Information Systems), 12(4), 64-97. 
(Quality Function Deployment). Os resultados obtidos evidenciam que os aspectos socioculturais exercem influência sobre as atividades definidas nas áreas-chaves de um KMMM. Além disso, é apontado o nível de influência (forte, moderado, fraco e inexistente) dos aspectos socioculturais identificados.

Palavras-Chave. Desenvolvimento Distribuído de Software; Aspectos Socioculturais; Gestão do Conhecimento; Modelos de Maturidade para Gestão de Conhecimento.

\section{Introdução}

Em busca de vantagem competitiva e cooperação, diversas organizações adotam atividades multilocais, multiculturais e globalmente distribuídas e, com isto, procuram aumentar a produtividade, melhorar a qualidade de produtos e reduzir custos [AUDY e PRIKLADNICKI, 2007; HUZTA et al., 2008; SILVA et al., 2010; VIVIAN et al., 2013; EBERT et al., 2016].

O Desenvolvimento Distribuído de Software (DDS) surgiu para tentar resolver vários problemas que existiam no desenvolvimento tradicional de software, notadamente no que se refere à alocação de recursos e ao melhor aproveitamento do tempo. Entretanto, a dispersão geográfica, a distância temporal e as diferenças sociais, elementos inerentes ao DDS, ampliaram alguns dos desafios existentes no desenvolvimento de software e, principalmente, adicionaram novas exigências acerca da comunicação entre os indivíduos participantes de um trabalho cooperativo [VIVIAN et al., 2013].

Além de adotarem o DDS, as empresas podem buscar, também, por outros meios que as apoiem na obtenção de vantagem competitiva e, consequentemente, em ganho de produtividade. Segundo Hsieh, Lin e Lin (2009) o conhecimento é um dos recursos mais importantes para a competitividade organizacional. Portanto, é importante que este recurso seja adequadamente gerido. Assim, tem se tornado cada vez mais comum a busca pelo que é conhecido como Gestão do Conhecimento (Knowledge Management - KM). A KM simplifica o processo de partilha, distribuição, criação, captura e compreensão do conhecimento da organização [DAVENPORT e PRUSAK, 1998]. Com essa gestão, é possível obter benefícios, dentre os quais podem ser citados: redução dos custos, tempo de produção e desenvolvimento de produtos, melhora na tomada de decisões, além de obter serviços com mais qualidade. Para que estes benefícios possam ser realmente alcançados, é necessário que a organização consiga executar a KM de forma eficiente. Diante desse fato, torna-se fundamental obter uma forma de medir o quão eficiente é a Gestão do Conhecimento de uma organização.

Modelos de maturidade são modelos criados com o objetivo de medir qual é o nível de maturidade de uma organização e quais são os requisitos para que a mesma possa melhorar e alcançar um próximo nível (mais elevado) de maturidade. Na literatura corrente, podem ser encontrados diversos Modelos de Maturidade para Gestão do Conhecimento (Knowledge Management Maturity Model - KMMM) [EHMS e LANGEN, 2002; KOCHIKAR, 2000; HSIEH, LIN e LIN, 2009]. Existem também alguns KMMM que são baseados no Capability Maturity Model - CMM (InfoSys KMMM [KOCHIKAR, 2000], Siemens KMMM [EHMS e LANGEN, 2002]). Dentre as características desses modelos, podem ser citados: a maioria possui de 4 a 8 níveis de 
maturidade (geralmente 5), sendo que esses níveis são sequencialmente ordenados, as organizações progridem de um nível para outro e nenhum desses níveis pode ser pulado.

A Gestão do Conhecimento é de extrema importância para o desenvolvimento distribuído/global de software [DESOUZA, AWAZU e BALOH, 2006; BODEN et al., 2009; ARSHAD et al., 2012; ISHII et al., 2013; BENINCA et al., 2015; SMITE et al., 2017]. Porém, o DDS possui características peculiares, decorrentes das três dimensões que o fundamentam, os quais impactam na utilização de um KMMM nesse contexto.

Vista a importância de KM no desenvolvimento distribuído e a existência de diversos desafios decorrentes dessa distribuição, foi gerada a seguinte questão de pesquisa: Os desafios existentes em DDS, mais especificamente os aspectos socioculturais de uma equipe distribuída, podem exercer influência sobre as atividades de um Modelo de Maturidade para Gestão do Conhecimento?

Para tal, estabeleceu-se como objetivo do artigo verificar se os aspectos socioculturais influenciam em um KMMM e qual o seu grau de influência, identifico os desafios de DDS que impactam diretamente na Gestão do Conhecimento e os aspectos socioculturais existentes em um ambiente DDS.

Quanto aos trabalhos na literatura relacionados a esse tema, não foi encontrado nenhum que abordasse este tema em específico. Os trabalhos relacionados ao KMMM apresentam, normalmente, apenas as características do modelo, não abordando a parte referente aos desafios que podem existir na utilização destes modelos. Lin, Wu e Yen (2012), apresentam alguns dos desafios para a utilização de um KMMM, porém apenas cita a existência de desafios relacionados aos aspectos socioculturais, não entrando em detalhes sobre o grau de influência, nem sobre quais são esses aspectos socioculturais.

Dessa forma, este artigo encontra-se estruturado em 5 seções, além desta introdutória. A Seção 2 apresenta o referencial teórico sobre Gestão do Conhecimento, Modelos de Maturidade, Desenvolvimento Distribuído de Software e Casa da Qualidade. Na Seção 3 é descrito o método de pesquisa adotado. A Seção 4 trata da influência dos Aspectos Socioculturais em um Modelo de Maturidade para a Gestão do Conhecimento. A Seção 5 apresenta as ameaças que podem comprometer a validade do trabalho. A Seção 6 contém as considerações finais com base em todo o estudo realizado, apresentando as conclusões e possíveis limitações deste trabalho.

\section{Referencial Teórico}

Nesta seção serão, brevemente, apresentados os conceitos que foram fundamentais para o desenvolvimento do trabalho ora apresentado.

\subsection{Gestão do Conhecimento}

A Gestão do Conhecimento ou Knowledge Management (KM) é uma área em constante evolução, que pode ser definida, segundo o European Guide to Good Practice in Knowledge Management (2004), como a gestão de atividades e processos que promovem o conhecimento para gerar aumento da competitividade por meio do melhor uso e da criação de fontes de conhecimentos individuais e coletivas. Oliveira et al. (2011) complementam que a Gestão do Conhecimento consiste de um conjunto de processos que visam a criação, armazenamento, disseminação e utilização do 
conhecimento, utilizados juntos com os objetivos de negócio, considerando as fontes de conhecimento internas e externas ao negócio.

Em Desenvolvimento Distribuído de Software, a Gestão do Conhecimento simplifica o processo de partilha, distribuição, criação, captura e compreensão do conhecimento por uma organização [BODEN et al., 2009; DORAIRAJ et al., 2012; ISHII et al., 2013; GHOBADI, 2015, SMITE et al., 2017].

A Gestão do Conhecimento pode trazer benefícios em relação à: melhoria da gestão dos projetos, melhoria na redução de custo, gestão eficiente dos recursos, melhoria da produtividade, melhoria da qualidade dos produtos, gestão das mudanças e maior colaboração e coordenação entre as equipes [DINGS $\varnothing$ YR et al., 2009; AHMED e AHSAN, 2014].

\subsection{Modelos de Maturidade}

Os modelos de maturidade permitem às organizações avaliarem sua evolução quanto a um determinado conteúdo [LIN, 2007]. Um modelo de maturidade descreve o desenvolvimento de uma entidade (pessoa ou organização) ao longo do tempo e tem as seguintes propriedades [SINHA, 2013]:

- O desenvolvimento de uma única entidade é simplificado e descrito com número limitado de níveis de maturidade (geralmente 4-6);

- Os níveis são caracterizados por certos requisitos que a entidade deve contemplar para atingir um determinado nível;

- Os níveis são sequencialmente ordenados, a partir de um nível inicial até um nível final (nível perfeito);

- Durante o desenvolvimento, a entidade progride de um nível para o próximo, sendo que nenhum nível pode ser deixado de fora;

- Os modelos de maturidade são análogos da abordagem de ciclo de vida. Cada entidade desenvolve através dos níveis ao longo do tempo até atingir a perfeição.

Paulk et al. (1995) identificaram diferenças existentes nas organizações maduras e imaturas, conforme apresentado na Tabela 1, os quais ajudam a compreender alguns dos benefícios que uma organização consegue obter ao se tornar madura, tais como maior controlabilidade e menos riscos, entre outros.

Um Modelo de Maturidade para Gestão do Conhecimento (Knowledge Management Maturity Model - KMMM) é um modelo de maturidade desenvolvido para avaliar a evolução da Gestão do Conhecimento. Entre algumas características sobre estes, estão: i) geralmente possui de 4 a 8 níveis (maioria com 5); ii) vários são baseados no CMM (Capability Maturity Model); iii) a maioria divide seus elementos de avaliação em áreas-chaves.

Na literatura há diversos KMMM's, dentre eles pode-se mencionar: KM3 [OLIVEIRA et al., 2011], KMMM [KURIAKOSE et al., 2011], KMCA [KULKARNI e FREEZE, 2004], Infosys KMMM [KOCHIKAR, 2000], Siemens KMMM [EHMS e LANGEN, 2002] e o KNM [HSIEH et al., 2009]. 
Tabela 1. Organizações Maduras x Organizações Imaturas [PAULK et al., 1995].

\begin{tabular}{|l|l|}
\hline \multicolumn{1}{|c|}{ Organizações Imaturas } & \multicolumn{1}{|c|}{ Organizações Maduras } \\
\hline $\begin{array}{l}\text { Ad hoc, processo improvisado por profissionais e } \\
\text { gerentes. }\end{array}$ & $\begin{array}{l}\text { Coerente com as linhas de ação, o } \\
\text { trabalho é efetivamente concluído. }\end{array}$ \\
\hline $\begin{array}{l}\text { Os Processos não são rigorosamente seguidos e o } \\
\text { cumprimento deles não é controlado. }\end{array}$ & $\begin{array}{l}\text { O processo é definido, documentado e } \\
\text { melhorado. }\end{array}$ \\
\hline Altamente dependente dos profissionais atuais. & $\begin{array}{l}\text { Com o apoio visível de alta } \\
\text { administração e de outras gerências. }\end{array}$ \\
\hline $\begin{array}{l}\text { Baixa visão do progresso e da qualidade dos } \\
\text { processos. }\end{array}$ & $\begin{array}{l}\text { Bem controlada, fidelidade ao processo } \\
\text { é objeto de auditoria e de controle. }\end{array}$ \\
\hline $\begin{array}{l}\text { A funcionalidade e a qualidade do produto podem } \\
\text { ficar comprometidas para que prazos sejam } \\
\text { cumpridos. }\end{array}$ & São utilizadas medições \\
\hline $\begin{array}{l}\text { Arriscado do ponto de vista do uso de novas } \\
\text { tecnologias. }\end{array}$ & Uso disciplinado da tecnologia. \\
\hline Qualidade difícil de prever. & $\begin{array}{l}\text { Gerentes monitoram a qualidade e os } \\
\text { processos que os produzem. }\end{array}$ \\
\hline
\end{tabular}

\subsection{Desenvolvimento Distribuído de Software e seus Desafios}

Durante muitos anos, o desenvolvimento de software ocorria de forma centralizada, com membros de uma equipe em um mesmo ambiente de trabalho. Mas, dependendo da empresa e da complexidade do software a ser desenvolvido, trabalhar utilizando apenas os recursos (humanos, materiais, etc.) locais pode ser difícil e custoso. Assim, para tentar melhorar o desenvolvimento, melhorar a alocação de recursos, diminuir o custo, entre outros fatores, surgiu a ideia de Desenvolvimento Distribuído de Software (DDS) [PRIKLADNICKI et al., 2004].

O DDS é o desenvolvimento de um software por uma equipe cujos membros estão trabalhando em locais geograficamente dispersos. Esta dispersão pode ser tanto dentro de uma mesma cidade, mesmo país, diferentes países ou, até mesmo, entre diferentes continentes [PRIKLADNICKI et al, 2004].

A adoção de DDS pode resultar em vários benefícios para a organização, tais como melhor alocação de recursos, Time-to-Market entre outros. Porém, para se obter os benefícios que o DDS fornece, se faz necessária a resolução de diversos problemas oriundos da dispersão dos membros da equipe [PRIKLADNICKI et al., 2004]. No entanto, o fato de trabalhar com uma equipe que tem os seus membros em locais diferentes pode acarretar em vários outros problemas, além daqueles existentes em um desenvolvimento centralizado.

Dentre os problemas, ocasionados pelo DDS, podem ser citados: o fuso horário diferente (que possibilita o trabalho 24 horas) pode causar problemas de comunicação entre os membros da equipe; a dispersão geográfica, dependendo do nível de dispersão, pode ocasionar problemas de conflito oriundos dos aspectos socioculturais (tais como idioma, cultura e religião) [PRIKLADNICKI et al., 2004; SILVA et al., 2010; MASSAGO et al., 2018].

Em Audy e Prikladnicki (2007) são descritos 28 desafios do DDS agrupados em: Processos, Pessoa, Tecnologia, Comunicação e Gestão, exposto na Tabela 2. Para cada um desses desafios também são apresentadas possíveis soluções para os mesmos. 
No contexto de DDS, as diferenças culturais podem resultar em problemas referentes à comunicação, colaboração, entre outros aspectos, o que pode resultar no fracasso de um projeto [AUDY e PRIKLADNICKI, 2007]. Na literatura, artigos referentes ao DDS [BABAR e LESCHER, 2014; CIBOTTO et al., 2011; HUZITA et al., 2008] citam que os aspectos sociais e/ou culturais são um dos fatores que impactam diretamente no desempenho de DDS. Porém, a grande maioria (PRIKLADNICKI et al., 2004; SILVA et al., 2010) somente cita alguns destes aspectos, não entrando em detalhes sobre estes ou somente explicando/citando alguns destes.

Tabela 2: Desafios do DDS [AUDY e PRIKLADNICKI, 2007; SILVA et al., 2010].

\begin{tabular}{|c|c|}
\hline Categoria & Desafios \\
\hline \multirow{11}{*}{ Pessoas } & Confiança \\
\hline & Conflitos \\
\hline & Diferenças culturais \\
\hline & Ensino de DDS \\
\hline & Espírito de equipe \\
\hline & $\begin{array}{l}\text { Formação de equipe e grupos / Identificação dos papeis e } \\
\text { responsabilidades }\end{array}$ \\
\hline & Liderança \\
\hline & Coordenação \\
\hline & Cooperação \\
\hline & Diferenças nos níveis de conhecimento \\
\hline & Tamanho da equipe \\
\hline \multirow{5}{*}{ Processo } & Arquitetura de software \\
\hline & Engenharia de requisitos \\
\hline & Gerencia de configurações \\
\hline & Processo de desenvolvimento \\
\hline & Assimetria nos processos, políticas e padrões \\
\hline \multirow{3}{*}{ Tecnologia } & Tecnologia de colaboração \\
\hline & Telecomunicação \\
\hline & Infraestrutura de TI / Diferenças nas tecnologias utilizadas \\
\hline \multirow{13}{*}{ Gestão } & Coordenação, controle e interdependência \\
\hline & Gestão de portfólios de projeto \\
\hline & Gerência de projetos \\
\hline & Legislação (incentivos fiscais e tributários) \\
\hline & Legislação (Propriedade intelectual, confidencialidade e privacidade) \\
\hline & Diferentes Stakeholders \\
\hline & Modelos de negócio \\
\hline & Seleção e alocação de projetos \\
\hline & Gestão dos escopos e mudanças \\
\hline & Visibilidade global \\
\hline & Trabalho sincronizado entre diferentes locais de trabalho \\
\hline & Gestão de riscos \\
\hline & Gestão de conhecimento \\
\hline \multirow{7}{*}{ Comunicação } & Awareness \\
\hline & Contexto \\
\hline & Dispersão Geográfica e Temporal \\
\hline & Estilo de comunicação \\
\hline & Formas de comunicação \\
\hline & Fusos horários \\
\hline & Barreiras linguísticas \\
\hline
\end{tabular}


No contexto deste trabalho, o conjunto de aspectos socioculturais se encontra dividido em três níveis: Perspectiva, Direcionador e os Aspectos [MASSAGO, 2015], os quais são descritos a seguir:

Perspectiva: macro visões de análise sob as quais os aspectos socioculturais podem ser observados/analisados por meio de um conjunto de direcionadores.

Direcionador: critérios que direcionam a visão de análise ou enfoque a ser dado sob as perspectivas.

Aspecto: elementos que caracterizam os aspectos socioculturais extraídos por meio do mapeamento sistemático realizado. Nem todos os aspectos elencados estão presentes neste nível, sendo considerados subitens dos Aspectos.

\subsection{Casa da Qualidade}

Casa da Qualidade, ou, no inglês, Quality Function Deployment (QFD) [PRASAD, 1998] foi, inicialmente, desenvolvido de forma que as necessidades dos clientes conduzam o desenvolvimento de um produto ou serviço. É um método dedicado a traduzir os requisitos do cliente em atividades para o desenvolvimento de produtos e serviços [CARNEVALLI e MIGUEL, 2008]. Existem vários estudos na literatura os quais tratam deste método, tais como o de Prasad (1998), Chan e Wu (2005) e Carnevalli e Miguel (2008).

Há diversos campos de aplicação da Casa da Qualidade, dentre os quais é possível citar: desenvolvimento de produto, gestão da qualidade, planejamento e análise da necessidade do cliente. Dessa forma, o QFD pode ser utilizado em diversas áreas: transportes, desenvolvimento de software, prestação de serviços, e na educação e pesquisas [CHAN e WU, 2002; SIVASAMY et al., 2016].

A matriz utilizada pelo QFD pode ser visualizada na Figura 1. Nela constam os principais componentes deste método, conforme apresentados por (PRASAD, 1998). Inicialmente, têm-se dois conjuntos: WHAT e HOW, os quais representam, respectivamente, as necessidades do cliente e as características necessárias de serem implementadas. Também, existe a matriz de relacionamento que deve ser preenchido com o nível de relacionamento existente entre os WHAT e os HOW. Os relacionamentos a serem utilizados são: nenhum relacionamento, relacionamento fraco, relacionamento moderado e relacionamento forte, sendo que para cada um destes é atribuído um valor. Estes valores normalmente consistem do seguinte conjunto: $\{0$ nenhum, 1 - fraco, 3 - moderado, 9 - forte\} [CHAN e WU, 2005].

Outra informação que deve ser inserida é o WHY, o qual refere-se ao nível de importância dos requisitos. Em outras palavras, qual é o nível de necessidade de cada um dos requisitos. Esta escala normalmente possui 5 valores, sendo que o 1 representa o menor grau de importância e o 5 representa o WHAT de maior importância [GOVERS, 1996].

A Casa da Qualidade, de posse do nível de importância dos requisitos, da matriz de relacionamento (WHAT $\mathrm{x}$ HOW) e do valor atribuído aos diferentes relacionamentos, realiza um cálculo matemático para verificar o nível de importância técnica $(\mathrm{HOW} \mathrm{MUCH})$ de cada uma das características necessárias. 
Assim, o QFD retorna o nível de importância de cada uma das características, baseado no relacionamento entre as características e as necessidades, bem como no nível de importância atribuída a cada uma dessas necessidades.

\section{Método de Pesquisa}

A pesquisa foi estruturada em três fases: i) Seleção do Modelo de Maturidade para Gestão do Conhecimento; ii) Análise de Influência dos Aspectos Socioculturais; iii) Aplicação do QFD.

A fase de Seleção do Modelo de Maturidade envolveu a definição de critérios de análise e a análise comparativa dos Modelos de Maturidade para Gestão do Conhecimento.

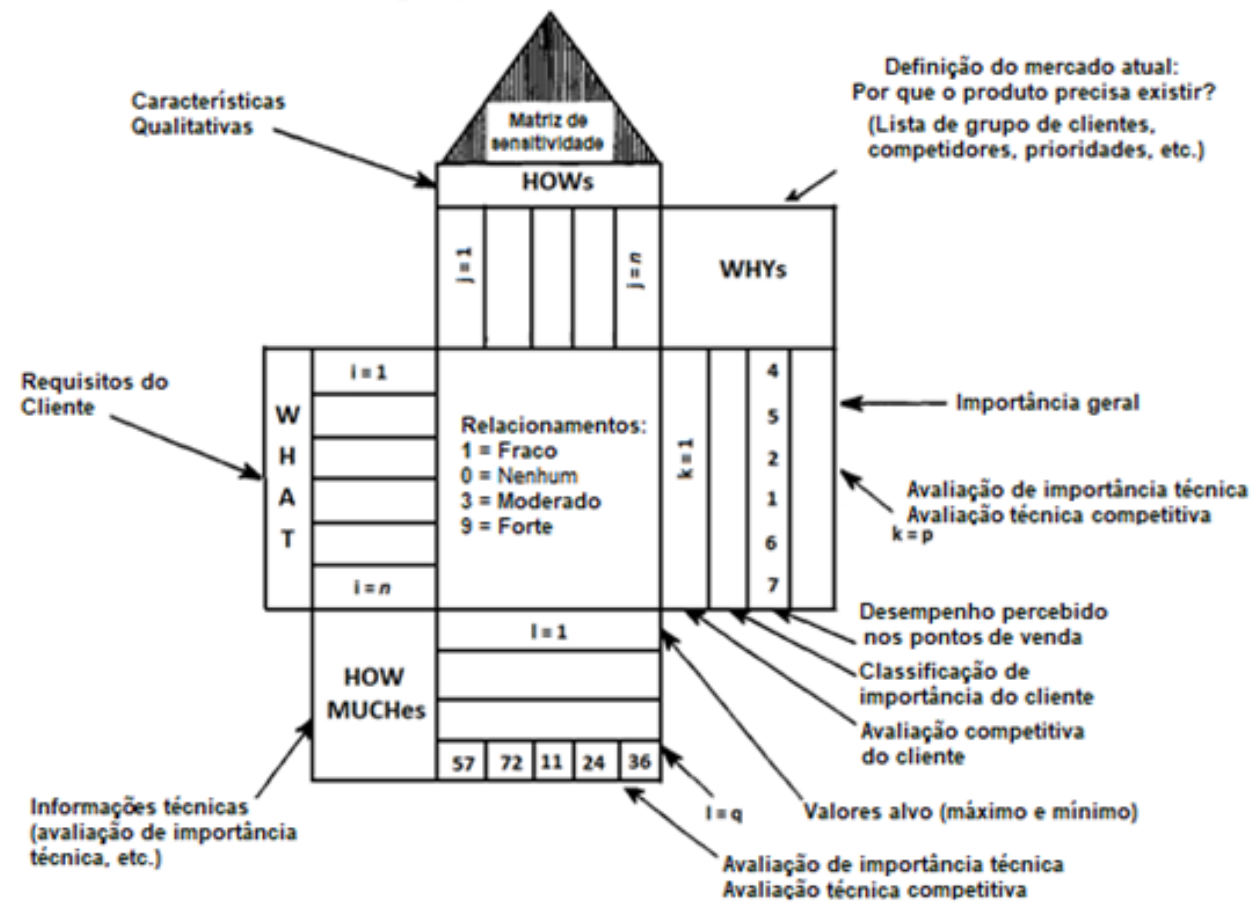

Figura 1. QFD [PRASAD, 1998].

A fase de Análise da Influência dos Aspectos Socioculturais foi conduzida por meio de um estudo empírico, que teve por objetivo verificar a existência de influência dos aspectos socioculturais sobre as áreas-chave do modelo de maturidade selecionado (KNM). As questões de pesquisa definidas foram: Q1. O conjunto de aspectos socioculturais influencia as áreas-chaves do KNM? Q2. Qual o nível de influência dos aspectos nas áreas-chaves do KNM? Nessa fase foram conduzidas as seguintes etapas: planejamento, teste piloto, coleta de dados e análise dos dados [FORZA, 2002].

- Planejamento: nessa etapa foi realizada a seleção dos participantes e a elaboração do instrumento de pesquisa.

oSeleção dos participantes: Os participantes da avaliação foram selecionados tomando-se como base o conhecimento desses, referentes ao Desenvolvimento Distribuído de Software e, se possível, também os 
relacionados aos Modelos de Maturidade, especialmente os KMMM. Neste estudo, foram convidados para participar, principalmente, profissionais de Maringá e região, caracterizando uma amostra não probabilística e por conveniência. A amostra por conveniência refere-se à aquisição de respostas por participantes que possuem disponibilidade e estão dispostas a colaborar [KITCHENHAM e PFLEGER, 2008].

oElaboração do instrumento de pesquisa: foi elaborado em duas partes: uma de caracterização do perfil dos participantes, cujo objetivo é a identificação do perfil e conhecimento dos participantes, referentes ao tema de pesquisa, e a segunda com perguntas que tem por objetivo adquirir os dados necessários para responder às questões de pesquisa. A escala adotada para as questões foi a Likert, que é usada para coletar a opinião sobre a relevância das perspectivas, dado que esta escala facilita a construção da pesquisa, coleta e análise de dados [LI, 2013]. A escala adotada é ordinal [JAMIESON et al., 2004] com cinco pontos, pois o uso de cinco pontos é usual e reduz o efeito "preguiça" ao responder o questionário [HARTLEY, 2014].

- Teste Piloto: teve por objetivo avaliar o instrumento de pesquisa (questionário) elaborado. O questionário foi validado, inicialmente, com docentes do grupo de pesquisa e, posteriormente, com um colaborador de uma empresa. As questões elaboradas foram analisadas, verificando sua clareza e se elas eram aplicáveis [MATA et al., 2014], concluindo que o questionário estava adequado.

- Coleta de Dados: o questionário foi disponibilizado na plataforma Google Docs e encaminhado por e-mail para 10 profissionais, ficando disponível por um período de 15 dias.

- Análise dos Resultados: após a coleta de dados foram aplicadas técnicas de estatística descritiva para destacar os acontecimentos e melhorar a compreensão sobre os dados obtidos.

A fase de Aplicação do QFD teve por objetivo realizar uma avaliação dos relacionamentos, bem como o nível de influência, entre os aspectos socioculturais presentes no DDS com as atividades do modelo de maturidade selecionado (KNM). Essa fase foi conduzida por meio de uma reunião com quatro pesquisadores, especialistas na área de DDS, os quais realizaram o julgamento dos relacionamentos e o nível de influência.

\section{Influência dos Aspectos Socioculturais em um Modelo de Maturidade para a Gestão do Conhecimento}

Esta seção destaca o estudo conduzido para identificar a influência dos aspectos socioculturais, presentes no DDS, em um modelo de maturidade para a Gestão do Conhecimento.

\subsection{Seleção do KMMM Base}

Visto a existência de diversos Modelos de Maturidade para Gestão do Conhecimento, cada qual com suas características, faz-se necessário identificar um que 
possa servir de base para ser utilizado no presente trabalho. Assim, foi executada uma análise destes modelos, levando-se em consideração os seguintes requisitos:

- Completude: refere-se à existência de documentação essencial à utilização do modelo, os quais incluem os níveis de maturidade, as áreas-chave do modelo, além do mecanismo de verificação do nível de maturidade. Esses documentos são necessários para que o mesmo possa ser utilizado pelas organizações interessadas.

- Disponibilidade: refere-se à disponibilidade das documentações necessárias, acima citadas. Diversos modelos presentes na literatura não disponibilizam toda a documentação necessária.

- Grau de abstração: um KMMM completo normalmente possui diversas atividades a serem executadas, além de ferramentas necessárias de serem implantadas. Assim, torna-se bastante difícil usar um KMMM por completo, em um estudo de campo para verificar cada um destes itens e compará-los com todos os elementos de outro conjunto uma vez que isto demanda muito tempo. Assim, seria interessante que o KMMM a ser utilizado possua diversos níveis de abstração de forma a possibilitar a escolha daquele nível que seja mais viável ao estudo.

Pelo fato de muitos dos modelos existentes serem desenvolvidos em ambiente acadêmico, utilizando-se basicamente de materiais teóricos como fundamentação, estes normalmente não são adequados à utilização real, faltando várias documentações necessárias, tais como detalhes da metodologia, método de avaliação, atividades necessárias de serem executadas, entre outros. Assim, diversos modelos apenas trazem consigo as áreas chaves e os níveis de maturidade do modelo, impossibilitando a sua utilização por parte das organizações interessadas.

Outros modelos como o da Siemens [EHMS e LANGEN, 2002] e da Infosys [KOCHIKAR, 2000] são desenvolvidos para serem utilizados internamente à organização ou para serem utilizados nos serviços prestados pelas mesmas, resultando na não disponibilização de todas as informações essenciais à sua utilização. Diante desse fato, estes modelos também não são adequados a serem utilizados como base para o desenvolvimento do presente trabalho. Entre os modelos identificados, aqueles que possuem documentação mais detalhada e disponibilizadas são: KM3 [OLIVEIRA et al., 2011], KMMM [KURIAKOSE et al., 2011], o KMCA e o KNM [HSIEH et al., 2009].

Destas, inicialmente, o KMMM desenvolvido por Kuriakose et al. (2011) no documento explicativo consta que o modelo ainda não tinha sido validado, como explicitado pelo autor.

Relacionado ao KMCA (Knowledge Management Capability Model), segundo consta em Glanzner e Audy (2012), existe uma diferença significativa entre um modelo de Maturidade e um modelo de Capacidade. O primeiro é organizado em estágios (ou níveis), considerando que a organização evolui de estágio implementando vários requisitos que, juntos, aumentam a sua maturidade. Em um modelo de capacidade, não existe conceito de estágio, mas de continuidade: uma organização pode escolher uma ou mais áreas do modelo para utilizar, sendo que a organização pode obter o nível máximo em uma área e possuir o mínimo em outra. Visto que o KMCA se utiliza dos termos "Modelo de Capacidade" e "Níveis de Capacidade", pressupõe-se tratar de um Modelo de Capacidade para Gestão do Conhecimento, e não um Modelo de Maturidade para Gestão do Conhecimento, o qual não é o foco do presente trabalho. 
Comparando o KM3 com o KNM, nota-se que o KNM é mais completo, possuindo 68 atividades a serem verificadas, comparadas aos 24 fatores do KM3, além de estar melhor organizado: no KNM existem 68 atividades, alocadas em 16 Key Areas, e cada uma destas atividades é relacionada com os níveis de maturidade dentro de um dos três pilares do modelo (Pessoas, Processos e TI); enquanto no KM3, os 24 fatores são vinculados aos níveis de maturidade, sendo que para cada nível, não existe agrupamento algum destes Fatores, nem está relacionado com uma área específica da organização. Além disso, existem mais atividades relacionadas ao nível operacional, quando comparado com o KM3, o que o torna mais favorável para a verificação dos aspectos socioculturais dos indivíduos que podem influenciá-lo. Um terceiro ponto a ser observado é o método de validação utilizado em cada um dos modelos: O KM3 realizou uma pesquisa com 28 especialistas por meio de uma apreciação crítica aonde se verificou as modificações necessárias, de forma teórica. Já o KNM foi aplicado em 30 empresas de diferentes áreas, sendo que 20 destas auxiliaram na criação do modelo, como forma de verificar o modelo e identificar a faixa de pontuação inicial a ser utilizado pelo framework de avaliação.

Outra característica que torna o KNM mais favorável à utilização no presente estudo é a existência de diferentes níveis de abstração. Essa abstração permite a avaliação em diferentes níveis de profundidade o qual favorece o estudo de campo a ser realizado. Assim, optou-se pela utilização do modelo KNM como base para o desenvolvimento deste trabalho.

\subsection{Análise da Influência dos Aspectos Socioculturais}

Relacionados à caracterização dos participantes, tem-se que a grande maioria (6), de um total de 10 participantes, estão localizados no município de Maringá, região norte do estado do Paraná. Outros participantes estavam localizados nas seguintes cidades: Guarapuava (1), Concórdia (1), Campo Mourão (1) e Palotina (1). Este conjunto foi obtido devido aos seguintes fatos: a mesma localização geográfica dos autores e dos participantes facilitou a comunicação e a participação no experimento; Maringá possui várias empresas com sede em outras regiões do país, tendo experiência com DDS. Outro fator que influenciou neste número de participantes foi o fato dos mesmos necessitarem possuírem experiência em DDS e/ou conhecimento a respeito de $\mathrm{KM}$, como forma de conseguir um resultado mais próximo da realidade atual das empresas, ao invés de resultados oriundos de conhecimentos teóricos. Sobre as outras características dos participantes, tem-se que a formação acadêmica da maioria dos participantes (50\%) é de Graduados, $20 \%$ de mestres, sendo que o restante marcou a opção outros: um especialista, um mestrando e um pós-graduado. Nota-se uma predominância de graduados, o que pode ser um indicativo de que diversos profissionais da área saem direto da universidade para o mercado de trabalho.

Relacionado à experiência em DDS, metade dos participantes consideram ter experiência básica, sendo que $20 \%$ tinham experiência intermediária e outros $20 \%$ declararam possuir experiência avançada. Apenas um dos participantes respondeu que não possuía experiência alguma em DDS. Este resultado pode ser um indicativo de que as organizações da região também estão adotando DDS, ou já experimentaram a sua utilização, mesmo que de maneira superficial. Os participantes também foram averiguados sobre seu conhecimento com relação à Gestão do Conhecimento. Como resultados obtidos, verificou-se que três deles não possuem conhecimento algum acerca 
de KM, sendo que quatro possuem conhecimento básico acerca do assunto. Esse resultado fornece indícios de que a gestão do conhecimento ainda não é um assunto muito abordado nas empresas produtoras de software da região de Maringá, ou essa gestão está sendo executada sem o conhecimento dos funcionários da empresa.

Com o intuito de averiguar a visão que os respondentes tinham em relação à relevância da identificação bem como a influência de aspectos socioculturais na execução de atividades em DDS, foram elaboradas perguntas solicitando aos participantes para assinalarem o grau de concordância em relação as seguintes afirmações:

- Afirmação 1: Os aspectos socioculturais influenciam nas atividades realizadas por equipes distribuídas, devido a possibilidade de integrantes das equipes possuírem características, tais como idiomas, culturas e costumes, bem distintos.

- Afirmação 2: A identificação dos aspectos que influenciam nas atividades realizadas por equipes distribuídas é relevante para planejar possíveis soluções a serem adotadas, como forma de amenizar os problemas que podem ser originados por esses aspectos.

Também foi inserida, no questionário, uma afirmativa sobre a importância da utilização de KM em DDS, como forma de reter e utilizar o conhecimento da organização:

- Afirmação 3: A Gestão do Conhecimento (KM) é importante em DDS para possibilitar reter e utilizar o conhecimento adquirido pela ou gerado na organização, como forma de obter vantagens competitivas frente aos concorrentes.

As respostas obtidas estão ilustradas na Figura 2. Para cada afirmação foram quantificadas no gráfico as respostas de acordo com o grau de concordância. Como pode ser observado, a maioria das respostas, às afirmativas citadas anteriormente, é de que os participantes concordam ou concordam completamente. Somente uma das respostas obtidas é diferente das outras, retornando como "indiferente" relacionado à importância de KM em DDS. Este último resultado "indiferente" pode ter sido originado devido à falta de conhecimento acerca de KM, visto que três dos participantes declararam não possuírem conhecimento acerca do assunto. 


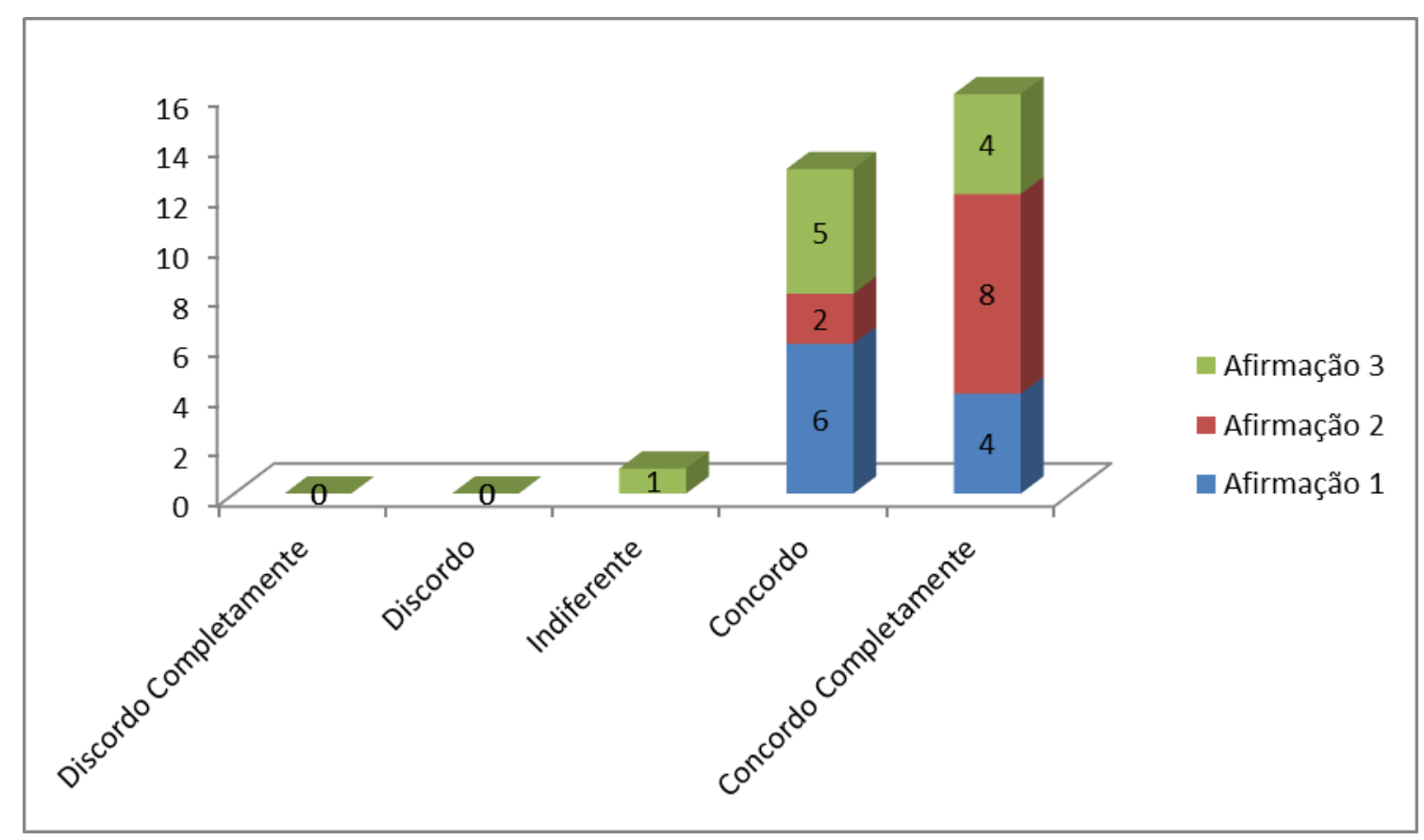

Figura 2. Resultado sobre a concordância dos Participantes com relação às Afirmativas.

Para verificar se o grau de experiência em DDS influenciou nas respostas obtidas, verificou-se o relacionamento da experiência em DDS com as respostas para cada uma das três afirmações. Esse relacionamento é mostrado nos gráficos das Figuras 3,4 e 5 .

Relacionado à existência de influência dos aspectos socioculturais nas atividades em DDS (Figura 3), nota-se que para aqueles que possuem os níveis básico e avançado não mostram sinais de diferença (nível básico: 2 pessoas concordam completamente e 3 pessoas concordam com a afirmação e no nível avançado: 1 pessoa concorda completamente e 1 pessoa concorda com a afirmação), porém, aqueles que responderam terem experiência intermediária em DDS declararam "concordo" com a afirmação.

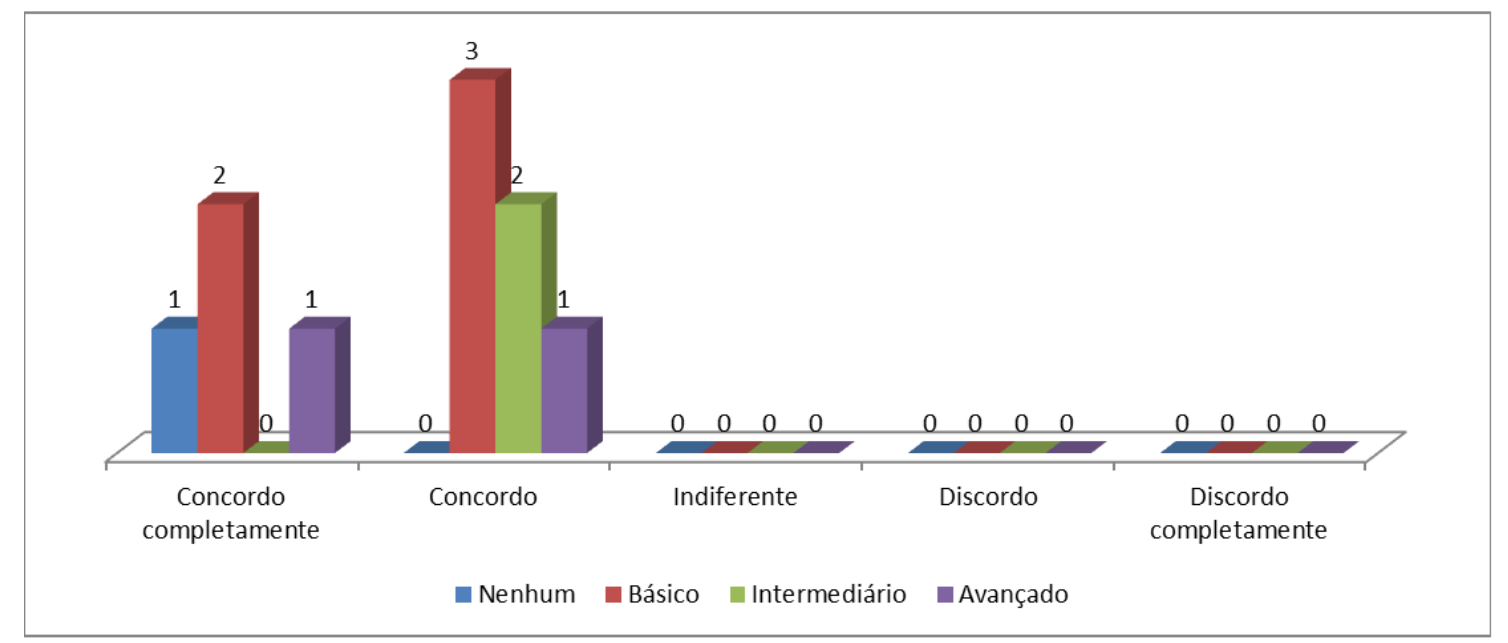

Figura 3. Resultado de acordo com a Experiência em DDS em relação a Afirmação 1. 
Para a Afirmação 2 (Figura 4), as respostas não foram tão proporcionais se comparadas com a anterior: nota-se uma predominância do "concordo completamente", tanto para aqueles com experiência avançada, quanto para aqueles com experiência básica. Nessa discussão não foi incluído o nível de experiência "Nenhum", visto que existia apenas um único indivíduo neste grupo, resultando na não existência de comparação dos resultados deste grupo.

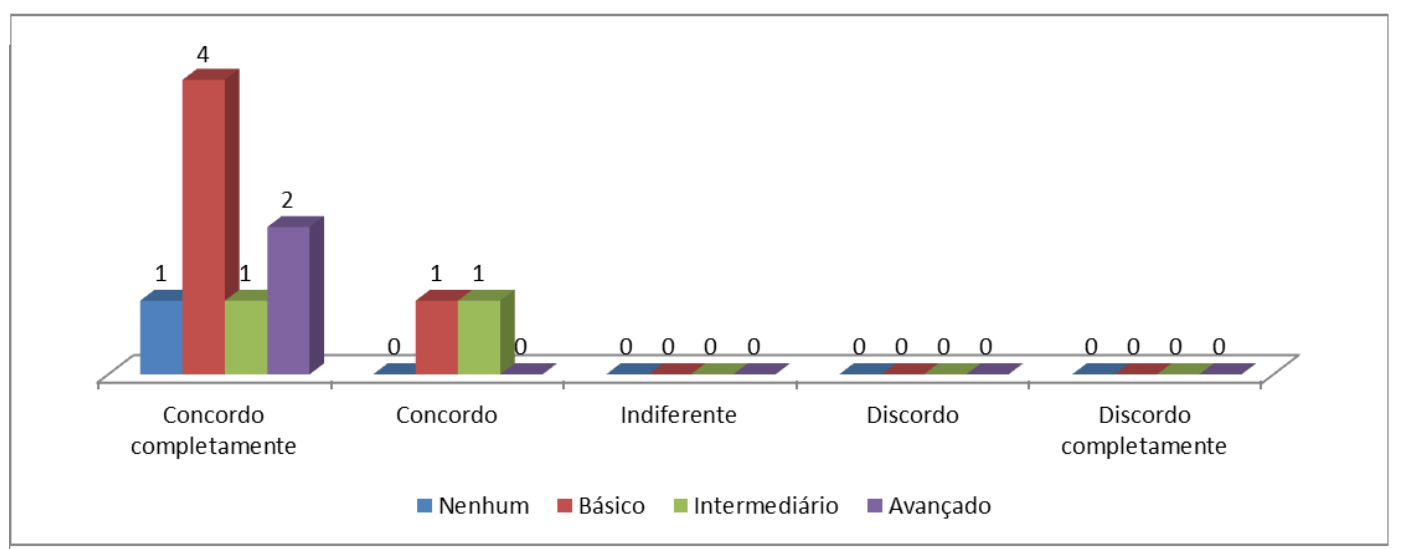

Figura 4. Resultado de acordo com a Experiência em DDS em relação a Afirmação 2.

Com relação a Afirmação 3 sobre a importância de KM em DDS (Figura 5): no nível avançado [1 concorda completamente e 1 concorda]; no intermediário [2 pessoas concordam] e no básico [2 concordam completamente e 2 concordam]. Aqueles com conhecimento avançado ou básico aparentemente responderam "concordo" e "concordo completamente" com a mesma proporção, enquanto que aqueles que declararam que possuíam conhecimento intermediário optaram pelo "concordo".

Estes resultados podem fornecer indícios de que o grau de experiência de DDS não influencia nas respostas "concordo" e "concordo completamente" relacionadas à Afirmações 1 e 3 . Porém, o resultado obtido pode ter sido influenciado pelo número reduzido de indivíduos, principalmente entre aqueles com experiência intermediária e avançada, os quais possuem dois indivíduos de cada.

Para a Afirmação 2, nota-se que a maioria com nível básico e todos com o nível avançado concordam completamente. Neste caso, percebe-se que aqueles com experiência básica e todos com experiência avançada têm a opinião de que a afirmação é completamente verdadeira, enquanto que aqueles com experiência intermediária ficaram divididos. Assim, pode-se concluir que, dentro do contexto deste experimento, os indivíduos que tem experiência básica e os que têm experiência avançada em DDS concordam completamente de que a identificação dos aspectos que influenciam nas atividades realizadas por equipes distribuídas é relevante para planejar possíveis soluções a serem adotadas, como forma de amenizar os problemas que podem ser originados por esses aspectos. 


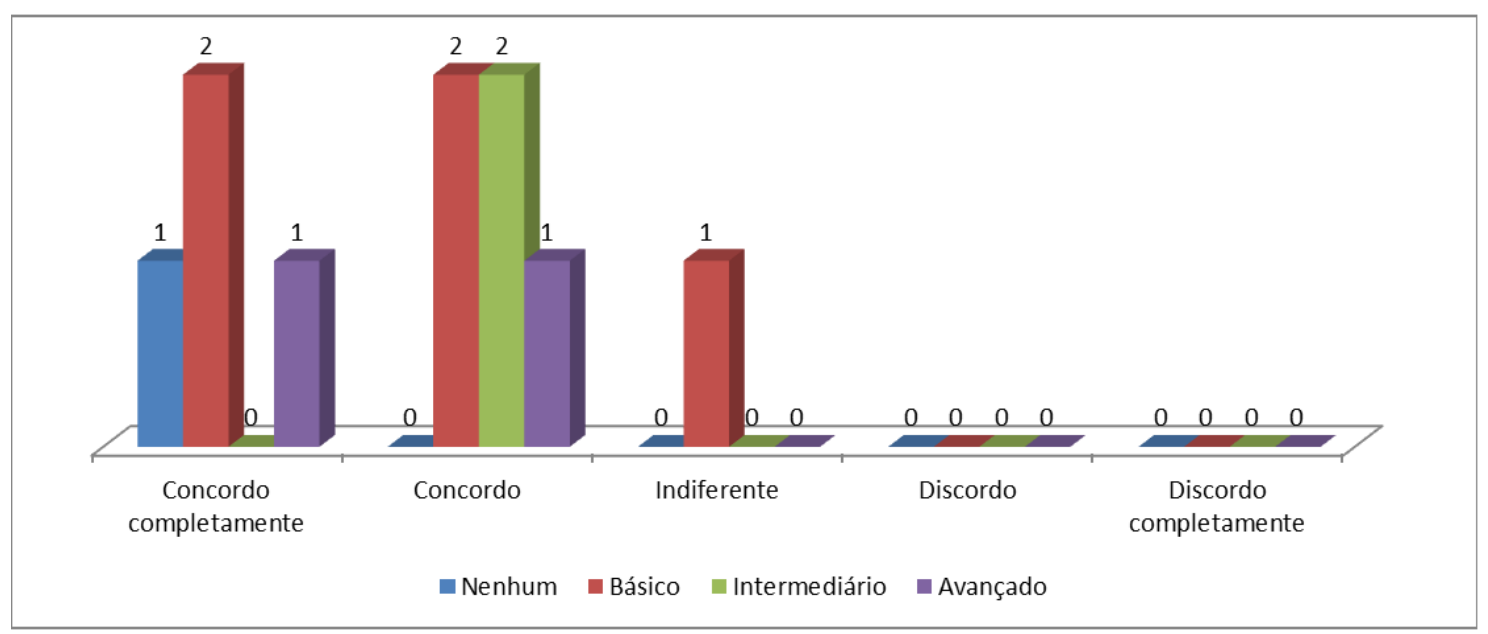

Figura 5. Resultado de acordo com a Experiência em DDS em relação a Afirmação 3.

Os resultados obtidos no estudo de campo, relacionados às três afirmações anteriores, também foram comparados com o conhecimento sobre KM que cada um dos participantes possuía, conforme as Figuras 6, 7 e 8.

Nota-se que o resultado é similar ao anterior, quando verificadas apenas as respostas "concordo" e "concordo completamente": para Afirmação 1 (Figura 6), as respostas estão distribuídas de maneira proporcional: tem-se [1 concorda completamente e 1 concorda], [2 concordam completamente e 2 concordam] e [1 concorda completamente e 2 concordam] para os níveis avançado, básico e nenhum, respectivamente.

Para a Afirmação 2 (Figura 7), nota-se que a maioria das respostas, independentemente do nível de conhecimento do participante, está concentrada principalmente no "concordo completamente".

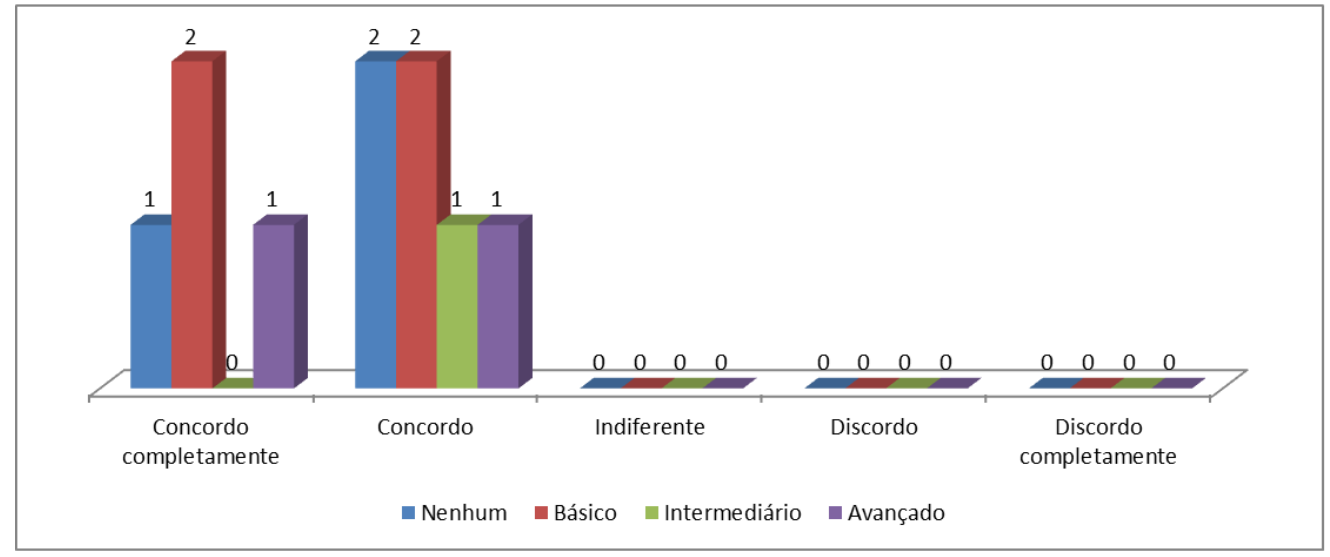

Figura 6. Resultado de acordo com o conhecimento sobre KM em relação a Afirmação 1. 


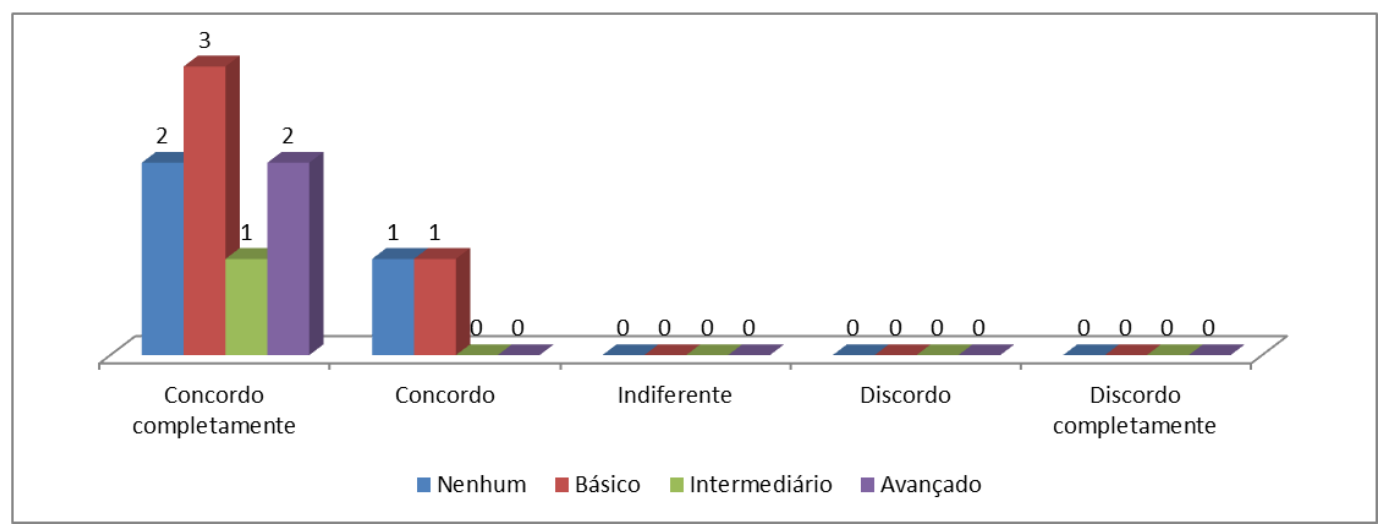

Figura 7. Resultado de acordo com o conhecimento sobre KM em relação a Afirmação 2.

Para a Afirmação 3 (Figura 8), tem-se os seguintes resultados: [1 concorda completamente e 1 concorda], [2 concordam completamente e 2 concordam] e [1 concorda completamente e 1 concorda] para os níveis avançado, básico e nenhum, respectivamente. Assim, para as Afirmações 1 e 3, o nível de conhecimento dos participantes não influencia na resposta "concordo" e "concordo completamente".

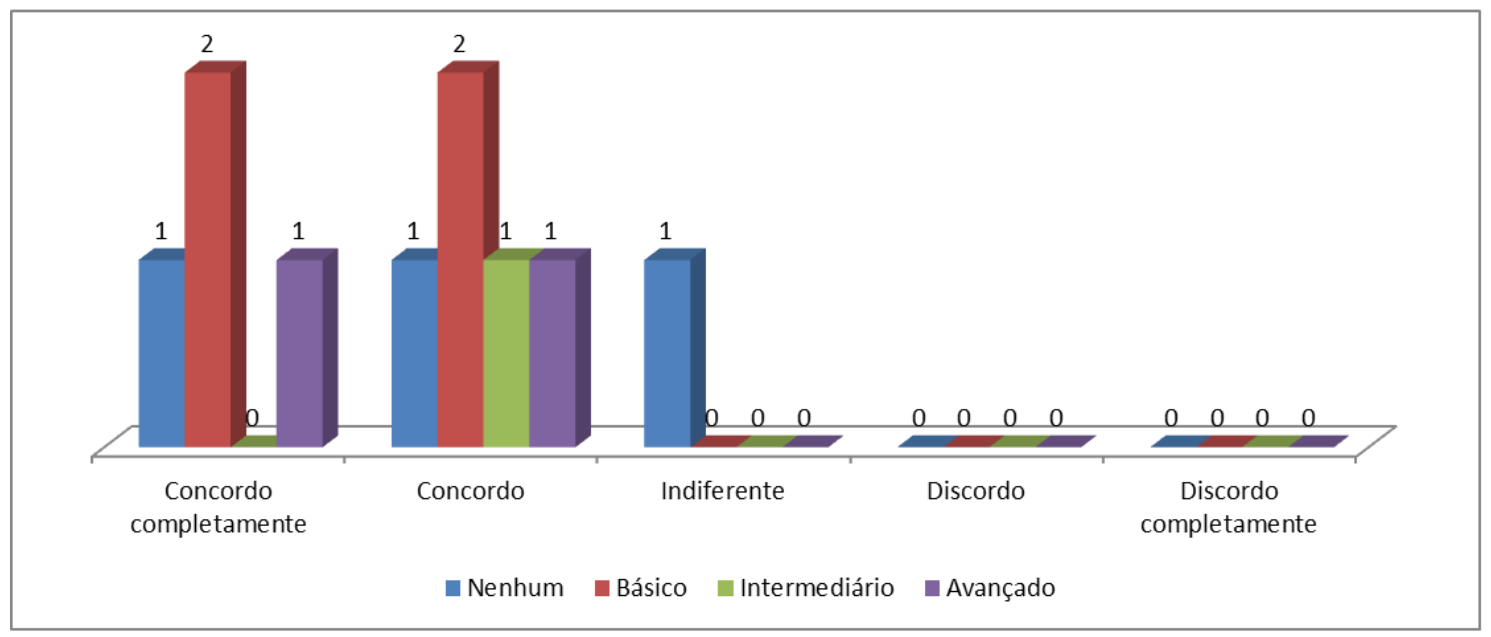

Figura 8. Resultado de acordo com o conhecimento sobre KM em relação a Afirmação 3

Relacionado à influência dos Direcionadores da Perspectiva Colaboração com as áreas-chaves do KNM, por meio dos resultados obtidos, foi verificado que os participantes consideram que a maioria das áreas-chave sofre efeito, em algum nível, dos aspectos relacionados à Comunicação entre os membros de uma equipe, conforme mostrado na Figura 9. Também pode-se observar que grande parte dos respondentes considera que a maioria das áreas-chave do KNM sofre influência forte do Direcionador Comunicação. Em três áreas-chave (Captura do Conhecimento; Proteção do Conhecimento; Infraestrutura de TI) o nível de influência identificada pela maioria dos participantes é a existência de influência fraca. Nota-se, também, que existem poucas respostas em que é verificada a inexistência de influência dos aspectos contidos no Direcionador Comunicação.

Este resultado corresponde a $3,75 \%$ do total de respostas. Com relação aos níveis de influência, tem-se: Fraca $=16,87 \%$; Moderada $=23,75 \%$; e Forte $=55,63 \%$. Assim, baseado nas respostas obtidas, pode-se concluir a existência de relacionamento 
entre os aspectos contidos no Direcionador Comunicação e as áreas-chave do KNM, dentro do contexto do presente estudo de campo realizado.

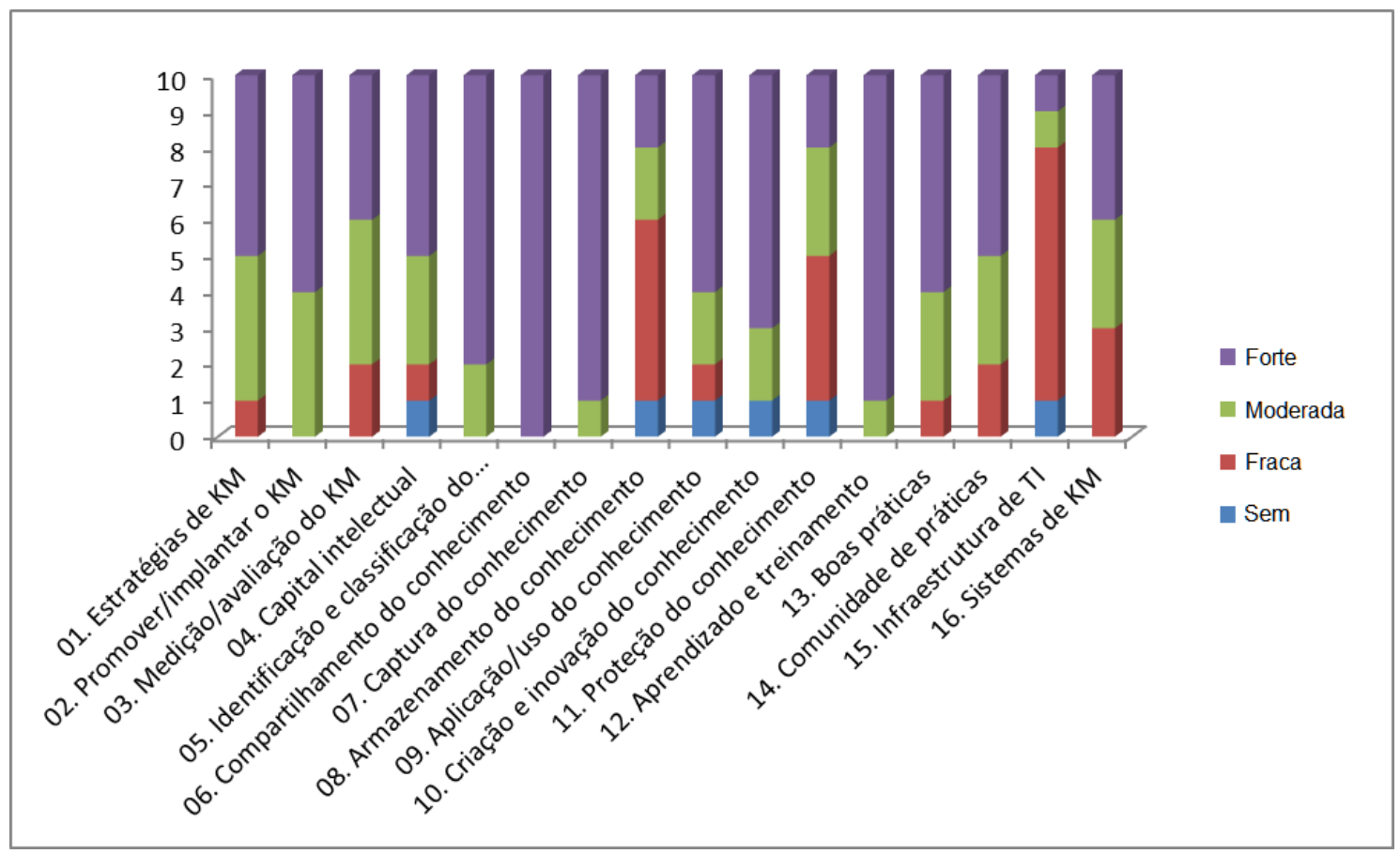

Figura 9. Resultado Grau de influência do Direcionador Comunicação nas Áreas-chave do KNM.

Com relação ao Direcionador Cooperação, nota-se que os participantes, em sua maioria, possuem a opinião de que a influência dos aspectos contidos neste Direcionador varia de moderada a forte, conforme exibido na Figura 10. Nesta parte da pesquisa, verifica-se a existência de apenas metade das respostas (3) que consideram a inexistência de qualquer relacionamento entre os aspectos do Direcionador Cooperação, quando comparado com o Direcionador Comunicação (6). Porém, também se nota a diminuição das respostas relacionadas ao nível Forte $(51,25 \%)$ e, em contrapartida, o aumento das respostas no nível Moderado (33,13\%). Contudo, visto que os níveis Forte e Moderado ainda possuem a maioria das respostas $(84,38 \%)$, pode-se concluir a existência de relacionamento entre os aspectos contidos no Direcionador Cooperação e as áreas-chave do KNM, dentro do contexto do presente estudo de campo realizado.

Por fim, tem-se os resultados relacionados aos níveis de influência exercidos pelos aspectos socioculturais do Direcionador Coordenação sobre as áreas-chave do KNM. Como pode ser observado na Figura 11, ainda ocorre a predominância do nível de relacionamento Forte em várias áreas-chaves, tais como "Identificação e classificação do conhecimento" e "Compartilhamento do conhecimento", mas nas áreaschave como "Infraestrutura de TI" e "Sistemas de KM" o relacionamento Fraco começa a predominar. Nota-se que neste Direcionador, a aparição do nível de influência Fraco é um pouco maior, mas ainda ocorre a predominância do Moderado e do Forte. 


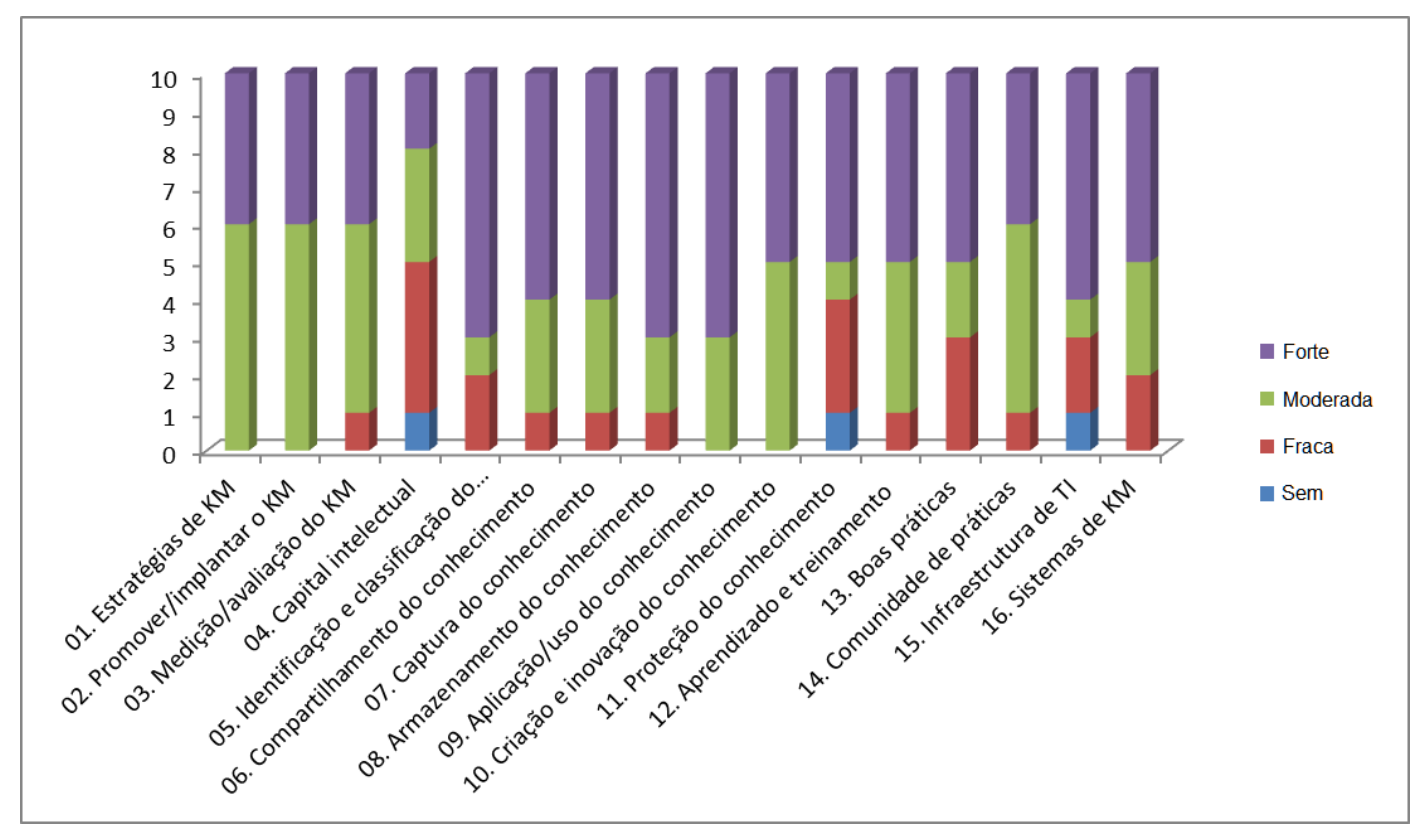

Figura 10. Grau de influência do Direcionador Cooperação nas Áreas-chave do KNM.

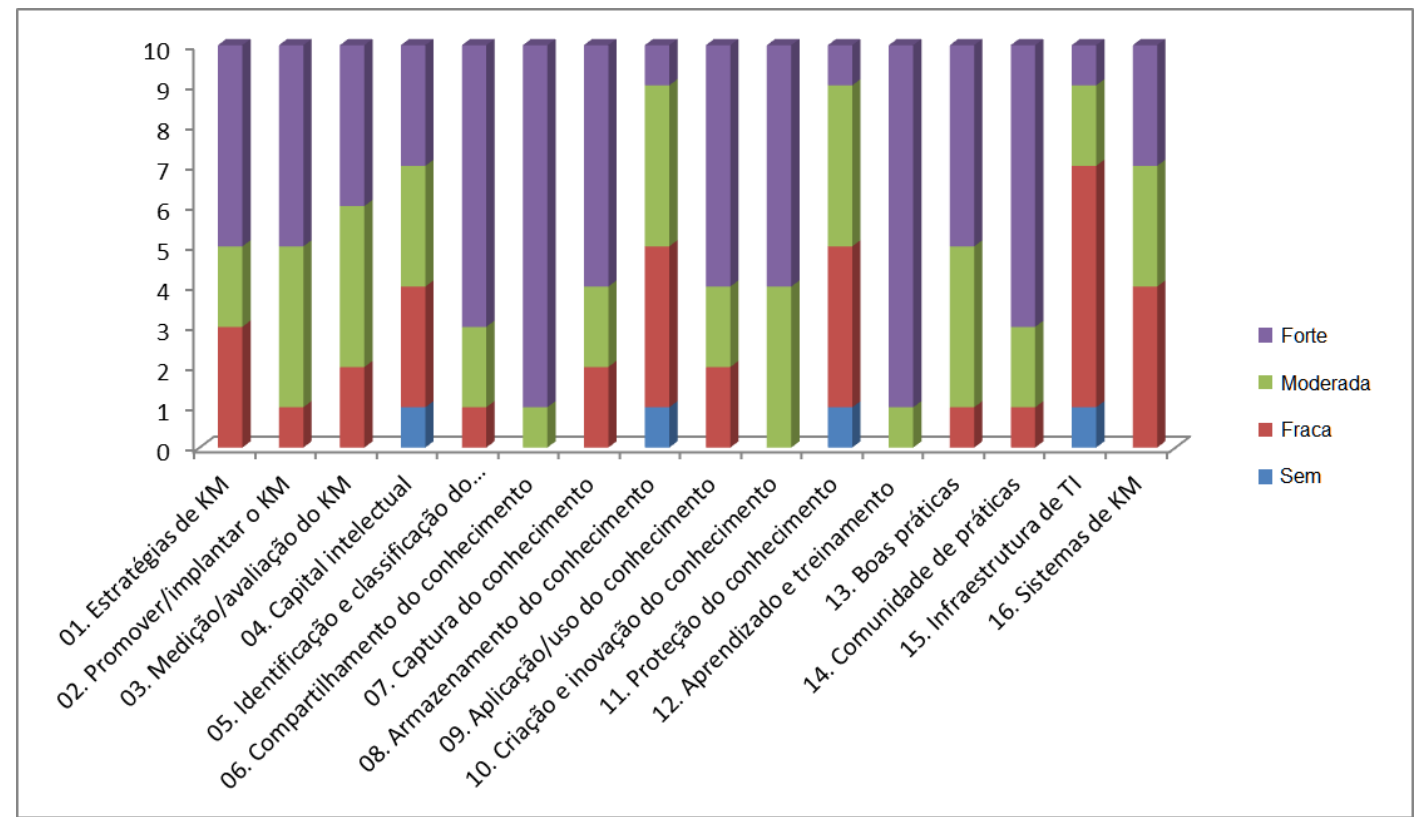

Figura 11. Percentual Grau de Influência do Direcionador Coordenação nas Áreas-chave do KNM.

Analisando as respostas para cada um dos níveis de influência dos três Direcionadores (Comunicação, Cooperação e Coordenação) da Perspectiva Colaboração; pode-se observar a existência de: Forte $=51,88 \%$; Moderado $=28,13 \%$; Fraco $=17,29 \%$; e Sem relacionamento $=2,71 \%$. Assim, tem-se que, com 97,29\% dos resultados, existe algum nível de relacionamento entre os aspectos socioculturais da Perspectiva Colaboração e as áreas-chave do KNM.

Diante deste número, pode-se afirmar que as áreas-chave do KNM são influenciadas, em algum nível, pelos aspectos socioculturais presentes na Perspectiva Colaboração, pelo menos no contexto do estudo de campo realizado. Assim, justifica-se um estudo sobre os aspectos socioculturais presentes em DDS e a influência destes nos 
modelos de maturidade existentes. Ainda, de acordo com o resultado obtido, nota-se a predominância do nível de relacionamento Forte, o que pode ser um indicador de que os aspectos socioculturais é um dos limitadores da utilização adequada de KMMM em DDS.

\subsection{Aplicação do QFD}

Após a escolha do KMMM a ser tomado como base (KNM), bem como a identificação dos aspectos socioculturais que podem estar presentes no DDS, e baseado nos resultados obtidos no estudo de campo realizado, foram elaboradas as Tabelas 3 e 4 . $\mathrm{Na}$ Tabela 3, relacionou-se as atividades, presentes no KNM, com os aspectos que influenciam a execução e utilização dessas atividades. Na Tabela 4, apresentou-se a legenda para os símbolos existentes na Tabela 3 que identificam a influência. Visto a existência de um grande número de aspectos socioculturais, optou-se por detalhar/aprofundar, no presente trabalho, os aspectos agrupados na Perspectiva Colaboração. Esta escolha deve-se ao fato de que um dos grandes desafios presentes no DDS é o estabelecido pela colaboração entre os diferentes indivíduos envolvidos.

Assim, como a Tabela 3 se tornou demasiadamente grande, decidiu-se exibir apenas um excerto no corpo deste presente artigo.

Como forma de conseguir realizar uma melhor avaliação dos relacionamentos e, também, do nível de influência dos aspectos nas diversas atividades do KNM, foi utilizado a Casa da Qualidade ou QFD.

Com base na especificação do QFD [PRASAD, 1998], para este presente artigo, os conjuntos utilizados são:

- WHAT - Conjunto de aspectos socioculturais;

- HOW - atividades do KNM;

- WHY - quantidade de artigos que citam cada um dos aspectos.

Diante das grandes proporções que a matriz de relacionamento terá no caso da utilização de todos os aspectos socioculturais, optou-se pela utilização de apenas um subconjunto deste. Assim, o conjunto WHAT consiste do conjunto dos aspectos relacionados à Perspectiva Colaboração. Este conjunto, relacionado às atividades do KNM, resultam em uma matriz de relacionamento de tamanho 12 × $64=768$ campos.

Para a valoração dos aspectos socioculturais quanto à sua importância (WHY), optou-se pela utilização do método de separação do conjunto em subconjuntos de tamanho iguais. Autores como Garcia (2010) e Landim (2003), sugerem a utilização de Distribuição de Frequência utilizando-se Intervalos de Classes, como forma de separar um conjunto numérico em subconjuntos. Assim, foi utilizada a frequência que os aspectos foram citados nos trabalhos elencados, como base para a sua classificação. Os limites superiores e inferiores dos subconjuntos foram definidos baseando-se no cálculo do Intervalo de classes, o qual utiliza-se o maior valor máximo subtraído do valor mínimo, dividido pelo número de classes (subconjuntos) necessário. Assim, utilizou-se o aspecto com maior número de referências (22 citações) e dividiu-se este pelo número de desejados (quantidade de valores necessários ao WHY): 22 / $5=4,4$. Dessa forma, obtivemos como conjuntos: $0 \vdash 5,5 \vdash 9,9 \vdash 14,14 \vdash 18$ e $18 \vdash 23$. 
Assim, obtivemos os valores a serem atribuídos a cada um dos aspectos socioculturais (WHY), os pesos de cada um dos relacionamentos $(0,1,3$ e 9) e os relacionamentos existentes entre os WHAT e os HOW's. De posse dessas informações, o QFD calcula o HOW MUCHes de cada elemento do HOWs: no caso da tabela gerada, retorna qual das atividades do KNM necessita de maiores atenções com relação aos aspectos utilizados na tabela.

Relacionado a esta primeira parte da Tabela, pela Casa da Qualidade, a atividade mais influenciada pelos aspectos socioculturais, é o 2.1, o qual resultou em 268,8 pontos. Esta pontuação, conforme mencionada anteriormente, é calculada pelo QFD, baseados no nível de relacionamento e nos pesos atribuídos a cada elemento no "WHAT".

Os relacionamentos identificados na Tabela 3 possuem as justificativas apresentadas nas subseções seguintes. Estas subseções foram divididas de acordo com os aspectos socioculturais, sendo que cada parágrafo apresenta a atividade do KNM e explica porque cada um dos aspectos influencia essas atividades do KNM.

Tabela 4: Legenda para os símbolos que identificam a Influência.

\begin{tabular}{|c|c|r|}
\hline $\begin{array}{c}\text { Símb } \\
\text { olo }\end{array}$ & Significado & $\begin{array}{r}\mathbf{P} \\
\text { eso }\end{array}$ \\
\hline$\odot$ & Relacionamento Forte & 9 \\
\hline 0 & $\begin{array}{c}\text { Relacionamento } \\
\text { Moderado }\end{array}$ & 3 \\
\hline $\boldsymbol{\Delta}$ & Relacionamento Fraco & 1 \\
\hline
\end{tabular}

Visto a grande quantidade de relacionamentos entre os aspectos socioculturais e as atividades do KNM, no corpo do texto serão apresentadas somente parte das justificativas, para outras informações consultar Massago (2015). O grau de influência foi atribuído levando-se em consideração o quanto cada aspecto possui relação com as atividades e quantos outros aspectos são levados em consideração para a implantação e execução destas atividades.

\subsubsection{Idioma}

Os desafios relacionados ao idioma, que podem existir em um projeto de DDS, podem estar relacionados com as seguintes atividades do KNM: 
Tabela 3. Influência da Percepção Colaboração sobre as atividades do KNM.

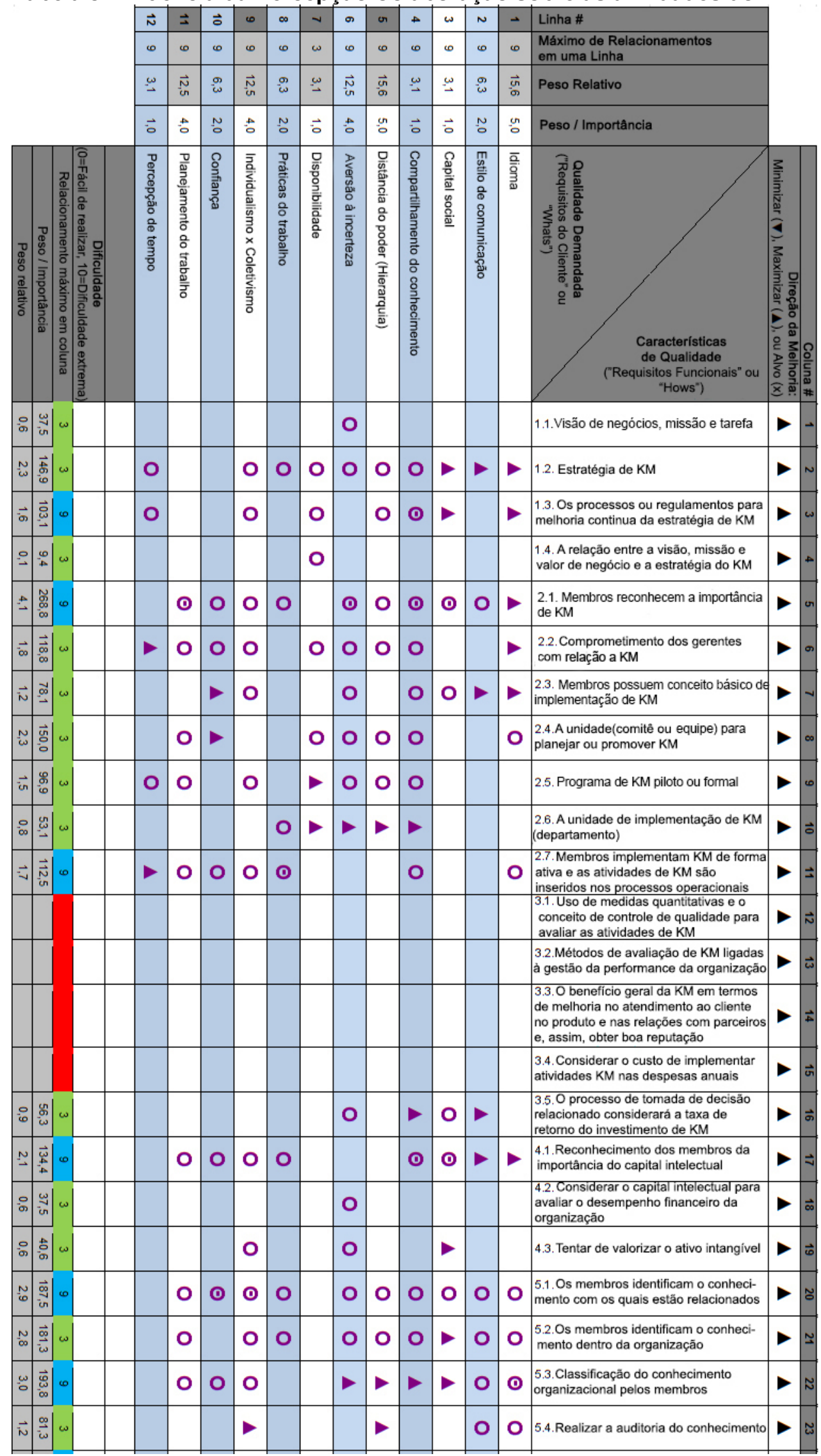


Estratégia de KM - item 1.2 [relacionamento fraco]. Para a implantação e utilização das estratégias de KM é necessário que estas sejam planejadas e incluídas: o objetivo da estratégia, as ferramentas necessárias, práticas de KM a serem adotadas, a definição dos repositórios, as pessoas a serem informadas sobre a estratégia a ser adotada e as decisões tomadas pelos gestores, treinamento necessário, linguagem padrão a ser utilizada. Esta estratégia deve ser adequadamente comunicada aos envolvidos.

Membros reconhecem a importância de KM - item 2.1 [relacionamento fraco]. Um indivíduo, para reconhecer a importância de algo, necessita obter informação a respeito, de forma a conseguir formar a sua própria opinião. No contexto de DDS, e mais especificamente de GSD, um dos fatores que influenciam na comunicação é a linguagem utilizada pelos indivíduos alocados em diferentes regiões do planeta, pois cada um pode utilizar uma linguagem diferente. Ainda, o nível de conhecimento que cada um dos membros de uma equipe possui com relação à língua escolhida para a comunicação influencia no repasse de informações, bem como na compreensão da informação.

A unidade (comitê ou equipe) para planejar ou promover KM - item 2.4 [relacionamento moderado]. A implantação de uma unidade responsável pelo planejamento de KM, seja um comitê ou uma equipe, necessita de recursos humanos a serem alocados para executar tal função/atividade. Para o bom funcionamento de uma equipe, principalmente no contexto de desenvolvimento global de software, é necessário que os indivíduos possuam uma linguagem de comunicação comum, a fim de conseguirem promover a troca de informação/conhecimento.

Membros implementam KM de forma ativa e as atividades de KM são inseridos nos processos operacionais ordinários - item 2.7 [relacionamento moderado]. Entre as atividades de KM, uma das principais refere ao ciclo do conhecimento. Um conhecimento deverá ser identificado, armazenado, compartilhado e (re)utilizado. Assim, principalmente para armazenar e compartilhar necessita-se da utilização de uma linguagem para tal. Dessa maneira, o conhecimento que os indivíduos possuem sobre a língua utilizada para as atividades de KM interfere no desempenho dessa atividade, bem como em possíveis atividades futuras, visto que, conhecimento armazenado de forma errônea ou incompleta (que pode ser originada pela não fluência da língua) pode impactar de forma negativa em atividades que utilizarão esse conhecimento.

\subsubsection{Estilo de Comunicação}

Membros reconhecem a importância de KM - item 2.1 [relacionamento moderado]. Para que os membros consigam compreender a importância da utilização de KM, um dos facilitadores é a transferência de conhecimento. A transferência de conhecimento faz uso de métodos de comunicação, a qual é influenciada pelas formas de comunicação utilizadas, uma vez que podem influenciar na interpretação da informação/conhecimento inserido nas mensagens/documentos trocados.

Os membros identificam o conhecimento com os quais estão relacionados item 5.1 [relacionamento moderado]. Para a identificação de conhecimento é necessário que ocorra o compartilhamento do conhecimento entre os membros. Esse compartilhamento, seja ele oral ou textual, sofre influência do estilo de comunicação adotado pelos indivíduos, o qual interfere na compreensão da mensagem entre os 
envolvidos. Por exemplo, se um indivíduo que leva em consideração o contexto em que envia uma mensagem a outra pessoa, ele deixará parte da informação implícita, mas se o receptor não levar em consideração o contexto da mensagem, irá perder parte do conteúdo da mensagem.

Membros participam de várias CoPs - item 14.1 [relacionamento forte]. Em uma Comunidade Prática $(\mathrm{CoP})$ existe muita troca de informação de forma que os membros consigam adquirir a informação desejada. Assim, é de fundamental importância que os membros saibam sobre os estilos de comunicação utilizados pelos outros integrantes dessa comunidade ou todos utilizem o mesmo estilo e, assim, evitar mal-entendidos. A compreensão da informação que espera repassar, para outros membros, bem como a aceitação do estilo de comunicação utilizado pode influenciar na permanência ou não de um indivíduo em uma comunidade.

\subsubsection{Capital Social}

Membros reconhecem a importância de KM - item 2.1 [relacionamento forte]. Para reconhecer a importância de algo é necessário conhecimento a respeito do assunto. Esse conhecimento pode ser obtido por meio de documentos ou outras pessoas. Além desse conhecimento, para algumas pessoas, a afirmação de alguém em que confiam já é o suficiente. Assim, em ambos os casos, rede de relacionamento ajuda no reconhecimento da importância de KM.

Membros possuem o conceito básico da implementação de KM - item 2.3 [relacionamento moderado]. Para conseguir obter conhecimento a respeito, uma das alternativas é o indivíduo que detêm esse conhecimento, o repassar aos demais indivíduos. Assim, os membros que possuem capital social mais amplo possuem maior chance de estarem relacionados com o detentor do conhecimento.

Os membros possuem uma cultura de compartilhamento do conhecimento, e com atitudes positivas - item 6.1 [relacionamento moderado]. Os membros, possivelmente, serão mais inclinados a compartilhar o seu conhecimento dentro do seu grupo de relacionamento. Além disso, atitudes positivas dependem da cultura individual (os indivíduos possuem suas próprias crenças, tradições, costumes...). Assim, conhecer as características individuais ajuda nesse quesito de "atitudes positivas" e as redes de relacionamento podem possibilitar a obtenção de conhecimento a respeito.

Os membros são capazes de aplicar o conhecimento interno para realizar a tarefa - item 9.1 [relacionamento moderado]. Para conseguirem aplicar os conhecimentos existentes, é necessário aprender a como executar essa atividade. Um dos métodos de aprendizagem que pode ser utilizado é solicitando a alguém que sabe repassar esse conhecimento. Uma rede de relacionamento "grande" pode possibilitar encontrar o detentor desse conhecimento mais rapidamente, além de facilitar no aprendizado, caso os indivíduos tenham uma relação de confiança.

\subsubsection{Compartilhamento do Conhecimento}

Estratégia de KM - item 1.2 [relacionamento moderado]. Para o bom funcionamento de uma estratégia de KM, é necessário que a mesma possibilite gerar adequadamente os conhecimentos e consiga disseminá-los. Assim, a cultura individual de compartilhar um conhecimento ou mantê-lo para si influencia tanto na obtenção 
quanto no compartilhamento. Portanto, é necessário que a estratégia inclua meios para mitigar as dificuldades de obtenção e disseminação de conhecimento.

Membros reconhecem a importância de KM - item 2.1 [relacionamento forte]. Uma das maneiras para que os membros reconheçam a importância é através do compartilhamento de conhecimento, que pode ser considerado como um dos elementos chaves de KM. Quem possui conhecimento a respeito do KM repassa-o aos demais membros de modo que estes consigam uma base teórica para evoluírem suas próprias ideias. Assim, é importante que o conhecimento seja repassado aos demais membros de modo que estes consigam utilizar o conhecimento compartilhado, evolua $\mathrm{o}$ conhecimento e novamente dissemine o conhecimento resultante.

Os membros têm uma cultura criativa e de inovação - item 10.1 [relacionamento moderado]. Pessoas que trocam informações com outras podem ser mais criativas, visto que possuem uma quantidade maior de informação a ser utilizada na elaboração de uma ideia. Nesse caso, a cultura de compartilhamento de conhecimento pode influenciar nessa troca de informação/conhecimento necessário. Além disso, mesmo que um indivíduo tenha ideias inovadoras, de nada adiantará se esta não fizer uso destas ou compartilhar com outras pessoas.

\subsubsection{Distância do Poder}

Estratégia de KM - item 1.2 [relacionamento moderado]. Dependendo do tratamento esperado pelos membros, quanto à hierarquia, podem ser utilizadas diferentes abordagens para melhorar o desempenho da estratégia de KM. Por exemplo, pessoas com baixo grau de distância do poder tendem a esperar tratamento igual, independente da hierarquia, enquanto que pessoas com alto grau neste aspecto tendem a possuir cultura do "manda-obedece" (pessoas com elevada hierarquia mandam, os outros somente obedecem).

Membros reconhecem a importância de KM - item 2.1 [relacionamento moderado]. Podem existir indivíduos que relutem em reconhecer a importância de KM, devido a diversos fatores: Pode haver indivíduos que não se sintam capazes de praticar as iniciativas de KM, nesses casos recomenda-se que esses indivíduos passem por um processo de capacitação, o que envolve comunicação. Já para os casos em que os indivíduos não acreditam na proposta de KM, a melhor maneira de lidar é estabelecendo uma relação de confiança, para reduzir a resistência. Uma maneira efetiva de fazer isso é por meio da comunicação. Na comunicação entre indivíduos, principalmente entre aqueles com hierarquia variada, um dos fatores que impacta é o grau de distância do poder entre estes indivíduos.

Comprometimento dos gerentes com relação a KM - item 2.2 [relacionamento moderado]. Existem indivíduos que obedecem facilmente à ordem vinda de uma hierarquia mais elevada, enquanto outros esperam tratamento igual independentemente da posição que ocupam. No primeiro caso, basta emitir uma ordem para que os gestores se comprometam com a utilização de KM, enquanto no outro caso, pode demandar mais tempo e planejamento.

Os membros possuem uma cultura de compartilhamento do conhecimento, e com atitudes positivas - item 6.1 [relacionamento forte]. Dependendo do nível de aceitação das diferenças, estas podem influenciar no compartilhamento de 
conhecimento, bem como na distinção de atitudes consideradas positivas ou não. Por exemplo, para um indivíduo com baixo grau de distância do poder, o tratamento igualitário entre os membros, independentemente da posição que ocupa, é uma atitude positiva, enquanto que para aqueles com alto grau de distância do poder a reverência e o tratamento mais formal para com os superiores são considerados atitudes positivas.

\subsubsection{Aversão à Incerteza}

Visão de negócios, missão e tarefa - item 1.1 [relacionamento moderado]. Para que a organização consiga atingir os seus objetivos é necessário que os seus membros trabalhem de forma a conseguirem isso. Um fator que pode dificultar isso é a aversão à incerteza. Dependendo da insegurança que os membros sentem em relação aos objetivos e dos meios para alcançá-los, pode fazer com que estes indivíduos se sintam desmotivados ou até fiquem relutantes em apoiar as decisões da organização.

Membros reconhecem a importância de KM - item 2.1 [relacionamento forte]. Para o reconhecimento da importância de algo novo, é necessário que os envolvidos consigam superar a insegurança que sentem em relação a ele. Diferentes pessoas se sentem inseguras em situações distintas, dependendo do conhecimento que possuem sobre o assunto e do ambiente aonde ele se desenvolveu. Assim, pessoas sem conhecimento do assunto ou com conhecimento parcial ou errado podem ser mais relutantes em reconhecer a importância da adoção de KM.

Os membros têm uma cultura criativa e de inovação - item 10.1 [relacionamento forte]. A aversão à incerteza pode influenciar os membros a serem criativos e inovadores. Um indivíduo com baixo grau de aversão à incerteza, que não fica inseguro facilmente, pode ser mais apto a formular e testar novas ideias. Por outro lado, podem existir pessoas que ficam inseguras facilmente e que busquem por novas maneiras de amenizar a insegurança que sentem, por meio de pesquisas sobre o assunto. Além disso, dependendo do grau de aversão à incerteza que possuem, os indivíduos podem possuir ideias inovadoras, mas não as apresentam aos demais membros por se preocuparem com os problemas que estas podem gerar caso não funcionem de acordo com o planejado.

\subsubsection{Disponibilidade}

Estratégia de KM - item 1.2 [relacionamento moderado]. Para o planejamento da estratégia de KM deve ser levado em consideração o tempo a ser utilizado pelos membros para as atividades relacionadas a KM. Dependendo do caso, pode ser necessário que alguns membros trabalhem fora do horário de expediente normal, mesmo que por um curto período de tempo. Assim, a disponibilidade, ou seja, se os membros estão dispostos ou não a trabalhar nesses horários, precisa ser levado em consideração ao planejar a estratégia de KM.

Programa de KM piloto ou formal - item 2.5 [relacionamento fraco]. Para a execução de um programa piloto pode ser necessário a realocação de recursos humanos, bem como de possíveis extensões nos horários de trabalho dos membros para inserir novas atividades. Isso é influenciado pela cultura relacionada à disponibilidade.

Membros participam de várias CoPs - item 14.1 [relacionamento moderado]. Algumas pessoas executam atividades relacionadas ao trabalho somente em horário 
normal de trabalho. Assim, podem existir indivíduos que não participem de CoPs devido à cultura de disponibilidade. No contexto de DDS, podem existir membros espalhados em diferentes regiões geográficas, dificultando encontrar um horário comum entre os membros.

\subsubsection{Práticas de Trabalho}

Estratégia de KM - item 1.2 [relacionamento moderado]. Existem indivíduos que preferem trabalhar utilizando determinadas ferramentas, diferentes das utilizadas na organização, ou trabalhar em casa em vez de na empresa. Assim, dependendo do caso, a escolha de um padrão de trabalho ou, até mesmo, deixar o horário mais flexível pode impactar no desempenho dos membros da equipe.

Membros reconhecem a importância de KM - item 2.1 [relacionamento moderado]. Dependendo do contexto de trabalho dos indivíduos estes podem sentir maior necessidade de gerenciar o conhecimento ou não. Por exemplo, um membro da equipe que trabalha sozinho em casa, pode necessitar que esteja ao seu alcance o conhecimento que precisa (como em um repositório), de preferência documentados, do que aqueles que trabalham em um mesmo espaço físico que os demais membros, onde é possível perguntar facilmente aos colegas ao lado.

Os regulamentos e processos para promover a inovação - item 10.3 [relacionamento fraco]. As práticas de trabalho utilizadas podem vir a interferir na inovação. Assim, uma estratégia que pode ser adotada é tentar adequar as práticas de trabalho utilizadas para se tornarem mais compatíveis com aquelas que os membros preferem ou estejam familiarizados. Há também a possibilidade de que haja a necessidade de aculturamento de novas práticas visando um aumento de desempenho ou até mesmo para obter certificações de qualidade.

Os membros são capazes de utilizar e-mail, internet e motores de busca item 15.1 [relacionamento forte]. Dependendo da preferência pelas práticas de trabalho, os membros podem já estar acostumados à utilização de diversas ferramentas ou não. Também é possível o surgimento de resistência à utilização de ferramentas dos quais não gostam, resultando no não aproveitamento dos resultados possíveis de serem obtidos com o uso destas.

\subsubsection{Individualismo $X$ Coletivismo}

Estratégia de KM - item 1.2 [relacionamento moderado]. Para a utilização de $\mathrm{KM}$, algumas das atividades que precisam ser implementadas refere-se à obtenção e compartilhamento de conhecimento. Esses dois conjuntos de atividades (pode existir mais de uma atividade relacionada à obtenção ou compartilhamento) são influenciadas pelo fator relacionado às características individuais no que tange ao repasse de informação. Existem pessoas individualistas, as quais possuem orientação a si própria, e que podem ser relutantes em disponibilizar/compartilhar o conhecimento que detêm. Também existem pessoas com a cultura do coletivismo, cuja orientação é para as metas e os objetivos comuns, os quais possuem caráter de compartilhamento de conhecimento. A estratégia de KM deverá prover planos para a captura/disseminação de conhecimento e, eventualmente, pode se deparar com problemas relacionados ao individualismo. Tais estratégias podem prover formas de conscientizar as pessoas de que elas também se 
beneficiarão com KM, além de tentar criar relacionamentos de amizade/confiança entre os membros, de forma a diminuir os impactos do individualismo.

Os membros possuem uma cultura de compartilhamento do conhecimento, e com atitudes positivas - item 6.1 [relacionamento forte]. No que tange ao compartilhamento de conhecimento que um indivíduo detém, a sua eficiência está ligada à vontade deste querer ou não fazê-lo. Indivíduos que querem repassar o conhecimento provavelmente irão fazê-lo de forma mais fácil, enquanto aqueles que não estão dispostos a fazê-lo podem não compartilhar o conhecimento completo ou, então, fazê-lo de forma difícil de interpretar.

Os regulamentos e processos para facilitar o compartilhamento do conhecimento - item 6.2 [relacionamento moderado]. Conforme mencionado anteriormente, o individualismo/coletivismo pode influenciar na decisão de compartilhar conhecimento. Assim, pode-se levar esse aspecto em consideração ao planejar formas de adquirir/repassar o conhecimento. Por exemplo, os membros individualistas podem tornar-se mais colaborativos no compartilhamento de conhecimento, se estes forem convencidos de que tal compartilhamento pode proporcionar benefícios que não teriam caso optassem pela retenção do mesmo.

\subsubsection{Confiança}

Membros reconhecem a importância de KM - item 2.1 [relacionamento moderado]. Para reconhecer a importância de algo é necessário conhecimento a respeito. Esse conhecimento pode ser oriundo de documentos ou outras pessoas. Existem, ainda, casos em que para reconhecer a importância basta ter a confirmação de alguém em quem confia: se confia em uma pessoa e essa pessoa diz que algo é importante, então esse algo é importante.

Membros possuem conceito básico de implementação de KM - item 2.3 [relacionamento moderado]. Para alguém realizar uma atividade é necessário que este(a) possua o conhecimento a respeito de como executá-lo. Esse conhecimento pode ser oriundo de documentos ou de outras pessoas e a confiabilidade sobre essa fonte interfere na aceitação ou não desse conhecimento. No caso de não confiar na fonte, normalmente, as pessoas irão buscar por novas fontes para ter a garantia de que a informação é verdadeira, o que pode resultar em um desperdício de tempo. O indivíduo que detêm a informação também pode se tornar receoso de repassar informação a quem não tem relação de confiança.

Os membros possuem uma cultura de compartilhamento do conhecimento, e com atitudes positivas - item 6.1 [relacionamento forte]. Para essa atividade, os membros podem se tornar receosos em repassar o conhecimento a alguém em quem não confiam. O mesmo pode ser aplicar às atitudes positivas: os indivíduos podem não ter atitudes consideradas positivas, com os indivíduos em quem não confiam.

Membros participam de várias CoPs - item 14.1 [relacionamento forte]. Visto que nessas Comunidades existe muita troca de informação/conhecimento, a confiança para com outros participantes pode definir a participação ou não de um indivíduo. Os membros, possivelmente, não se sentiriam à vontade para participar abertamente e expressar suas ideias na presença de uma pessoa na qual não confia. 
O regulamento ou processo para encorajar os membros a participar das CoPs - item 14.2 [relacionamento moderado]. A falta de confiança é um fator que impede a participação, criar laços de confiança pode ser uma estratégia que pode ser utilizada para incentivar os membros a marcarem presença nas CoPs.

\subsubsection{Planejamento do Trabalho}

A unidade (comitê ou equipe) para planejar ou promover KM - item 2.4 [relacionamento moderado]. Para a implantação de uma unidade para executar o planejamento e/ou promover a gestão do conhecimento, é necessário que os indivíduos que irão compô-lo saibam do tempo de duração, objetivos e os resultados que a organização espera obter com a utilização de KM e, ainda, que estes indivíduos sejam capazes de planejar/promover esta Gestão de acordo com os objetivos de uma organização. Assim, uma das características que pode influenciar no resultado obtido pela unidade depende do planejamento utilizado, tais como tempo de investimento e carga-horária a ser utilizada pelos indivíduos.

Os membros possuem uma cultura de compartilhamento do conhecimento, e com atitudes positivas - item 6.1 [relacionamento forte]. Um aspecto sociocultural que impacta diretamente nos membros de uma equipe é o fato destes possuírem, ou planejem possuir, a cultura de compartilhamento de conhecimento, além do fato de que atitudes positivas podem definir a visão que estes têm para com o seu futuro dentro da organização. Dependendo do planejamento do indivíduo com relação ao seu futuro, ou a falta de planejamento, este pode ou não realizar diversas ações dentro da organização, incluindo o compartilhamento de conhecimento e a questão relacionada a possuir/utilizar/gerar atitudes positivas.

Os membros têm uma cultura criativa e de inovação - item 10.1 [relacionamento fraco]. O planejamento a curto ou a longo prazo (tempo de investimento) pode ser um dos pontos que impacta se um membro da equipe possui uma cultura de inovação e é criativo. Isso se deve ao fato de que podem existir diferenças sobre as ideias que um indivíduo que planeja a longo prazo pode apresentar (possivelmente ideias com resultados a longo prazo) com aquelas que são oriundas dos indivíduos imediatistas (possivelmente ideias que "surgiram" na hora).

\subsubsection{Percepção de Tempo}

Estratégia de KM - item 1.2 [relacionamento moderado]. Dependendo da existência de indivíduos que conseguem executar várias atividades em paralelo ou não, a estratégia pode necessitar de adaptações para o contexto dos membros envolvidos, ou necessitar de treinamento a respeito.

Os membros usam todos os tipos de canais de aprendizagem para conduzir a aprendizagem de conhecimentos - item 12.1 [relacionamento forte]. A possibilidade de executar diferentes atividades de maneira simultânea pode possibilitar a utilização de diferentes canais de aprendizagem simultaneamente, ou facilitar a utilização destes. Mas isso não implica que aqueles com percepção monocrômica não consigam utilizar todos esses canais, mas apenas que estes indivíduos podem demorar mais tempo para essa utilização. 


\section{Ameaças à Validade}

As ameaças que podem comprometer a validade do estudo conduzido referem-se à: validade conclusiva, validade construtiva, validade interna e validade externa [SHULL et al., 2002].

A validade interna compreende os fatores relacionados aos participantes, tais como motivação, cansaço, entre outros, os quais podem interferir nas respostas obtidas. Além disso, diferenças entre os participantes: relacionados à experiência profissional com DDS, modelos de Maturidade e KM, além do nível de formação acadêmica, também podem impactar. No entanto, o fato de os participantes serem voluntários mitiga as ameaças, pois estão realmente interessados em participar da pesquisa, conforme destacado por El-Attar e Miller (2009). Os possíveis erros relacionados ao instrumento de pesquisa foram mitigados por meio da avaliação do material por especialistas (tanto do meio acadêmico quanto industrial) [SJOBERG et al., 2007].

A validade externa refere-se ao fato do experimento ter sido realizado em empresas brasileiras, cujas filiais também são deste país. Assim, as dificuldades nos projetos, identificados pelos participantes, podem não corresponder a aqueles que possivelmente seriam identificadas em grandes multinacionais.

As principais ameaças a validade construtiva estão relacionadas com à influência do pesquisador e à variação de comportamento dos participantes [MADEYSKI, 2010]. A influência do pesquisador foi atenuada devido à não interação entre os participantes do estudo e a variação de comportamento não ocorreu, visto que o pesquisador não acompanhou os participantes durante o preenchimento do questionário.

A validade conclusiva pode ser afetada pelo número de participantes presentes $(n=10)$ neste estudo. Esse tipo de ameaça ocorre devido à dificuldade de se obter participantes do meio industrial para participar desse tipo de estudo. Uma forma de mitigar essa ameaça é replicar o estudo empírico, considerando empresas e profissionais de outras regiões.

\section{Considerações Finais}

Tendo como objetivo identificar a existência de influência dos aspectos socioculturais sobre um Modelo de Maturidade para Gestão do Conhecimento, este artigo apresentou um estudo de campo referente ao assunto. Um KMMM é um modelo construído com o propósito de avaliar o nível de maturidade, referente à Gestão do Conhecimento, de uma entidade. Visto que autores como Desouza, Awazu e Baloh (2006) defendem a importância de gerenciar o conhecimento em ambientes DDS, e que um KMMM fornece meios de avaliar e evoluir a Gestão do Conhecimento, é importante verificar a influência que estes modelos estão sujeitos, no que se refere aos aspectos particulares de DDS. Um destes aspectos está relacionado às características sociais e culturais dos diferentes indivíduos participantes do DDS.

Assim, a pesquisa identificou os diferentes aspectos socioculturais presentes na literatura, os quais podem estar presentes no desenvolvimento distribuído de software. Estes aspectos também foram subdivididos em grupos, como forma de facilitar a sua compreensão e sua utilização. 
Outro passo executado foi a verificação da existência de influência de um conjunto de aspectos socioculturais nas áreas-chave do modelo KNM. Esta verificação foi executada por meio de um estudo de campo realizado com profissionais da região de Maringá, os quais possuem experiência em DDS e/ou conhecimento acerca de KM. Neste estudo realizado obteve-se como resultado de que a Perspectiva Colaboração influencia as áreas-chaves do KNM. O resultado final mostra que 97,29\% das áreas chaves sofrem influência dos aspectos socioculturais da Perspectiva Colaboração, sendo que foi possível observar a existência dos seguintes de relacionamento: Forte $=51,87 \%$; Moderado $=28,12 \%$; Fraco $=17,29 \%$; e Sem relacionamento $=2,71 \%$.

Diante deste resultado, o estudo de campo realizado fornece evidência de que aspectos socioculturais possuem influência sobre um modelo de maturidade para gestão do conhecimento.

As principais contribuições são: i) descrição dos aspectos socioculturais presentes na literatura; ii) identificação dos aspectos e relacionamento com os desafios DDS; iii) verificação da evidência da existência de influência dos aspectos socioculturais (da Perspectiva Colaboração) no KNM e o seu nível de influência (Forte, Moderado, Fraco e inexistente); iv) verificação da influência dos aspectos socioculturais (da Perspectiva Colaboração) sobre as atividades do KNM.

As limitações deste estudo referem-se à: ii) domínio da pesquisa de campo: o conjunto de participantes do estudo de campo utilizado foi de profissionais principalmente da região de Maringá, no Paraná. Embora o número de participantes seja reduzido (10), era necessário que estes possuíssem/tivessem características/conhecimentos/experiência específica: DDS e KM. Assim, o grupo selecionado é bastante seleto. No entanto, sabe-se que é importante considerar o caso em que os participantes estejam atuando em nível global, quando algumas características culturais como, por exemplo: ética/moral, costumes, entre outros seriam mais fortes e que provavelmente poderiam revelar resultados distintos dos que foram aqui apresentados. iii) o aprofundamento do tema: os relacionamentos estabelecidos entre a Perspectiva Colaboração e as atividades do KNM carecem de uma análise envolvendo um grupo maior de participantes de modo a realizar possíveis ajustes, se for o caso.

\section{Referências}

Ahmed, A.; Ahsan, A. (2014) An Integrated Organizational Knowledge Management Framework (IOKMF) for Knowledge Creation and Usage. Journal of Strategy and Performance Management, v. 2, n.1, p. 17-30.

Arshad, S.; Usman, M.; Ikram, N. (2012) Knowledge Management Practices in GSD: A Systematic Literature Review. In: The Seventh International Conference on Software Engineering Advances (ICSEA), At Lisbon, Portugal.

Audy, J. L. N.; Prikladnicki, R. (2007) Desenvolvimento Distribuído de Software: Desenvolvimento de Software com Equipes Distribuídas, Rio de Janeiro: Campus. 2. ed.: Elsevier.

Babar, M. A.; Lescher, C. (2014) Editorial: Global software engineering: Identifying challenges is important and providing solutions is even better. Information and Software Technology, Butterworth-Heinemann, v. 56, n. 1, p. 1. 
Beninca, R.; Huzita, E. H. M.; Galdamez, E. V. C.; Leal, G. C. L.; Balancieri, R.; Massago, Y. (2015) Knowledge Management Practices in GSD A Systematic Literature Review Update. In: International Conference on Enterprise Information Systems (ICEIS), Barcelona.

Boden, A. et al. (2009) Knowledge management in distributed software development teams - does culture matter?, In: Proceedings of the 2009 Fourth IEEE International Conference on Global Software Engineering. Washington, DC, USA: IEEE Computer Society, (ICGSE ’09), p. 18-27.

Carnevalli, J. A.; Miguel, P. C. (2008) Review, analysis and classification of the literature on qfd-types of research, difficulties and benefits. International Journal of Production Economics, Elsevier, v. 114, n. 2, p. 737-754.

Chan, L. K.; Wu, M. L. (2005) A systematic approach to quality function deployment with full illustrative example, Omega, Elsevier, v. 33, n. 2, p. 119-139.

Chan, L. K.; Wu, M. L. (2002) Quality function deployment: A literature review. European Journal of Operational Research, Elsevier, v. 143, n. 3, p. 463-497.

Cibotto, G. et al. (2009) Uma análise da dimensão sociocultural no desenvolvimento distribuído de software. In: Workshop Olhar Sociotécnico sobre a Engenharia de Software (WOSES 2009), Ouro Preto, MG.

Davenport, T. H.; Prusak, L. (1998) Working knowledge: How organizations manage what they know, [S.1.]: Harvard Business Press.

Desouza, K. C.; Awazu, Y.; Baloh, P. (2006) Managing knowledge in global software development efforts: Issues and practices. IEEE software, IEEE Computer Society Press, v. 23, n. 5, p. 30-37.

Dingsøyr, T.; Bjørnson, O. F.; Shull, F (2009) What Do We Know about Knowledge Management? Practical Implications for Software Engineering, In: IEEE Software, v. 26, n. 3, p. 100-103.

Dorairaj, S.; Noble, J.; Malik, P. (2012) Knowledge management in distributed agile software development", In: IEEE. Agile Conference (AGILE), p. 64-73.

Ebert, C.; Kuhrmann, M.; Prikladnicki, R. (2016) Global Software Engineering: An Industry Perspective. IEEE Software, v. 33, n. 1, p. 105-108.

El-Attar, M.; Miller, J. (2009) A subject-based empirical evaluation of SSUCD's performance in reducing inconsistencies in use case models. Empirical Software Engineering, v. 14, n. 5, p. 477-512.

Forza, C. (2002) Survey research in operations management: a process based perspective, International Journal of Operations and Production Management, v. 22 n: 2, p.152-194.

Garcia, A. C. (2010) Tópicos de Estatística Básica, 1. Ed, Editora Clube de Autores.

Glanzner, R. A.; Audy, J. L. N. (2012) 2dam-wave: An evaluation method for the wave capability model, In: IEEE. 2012 IEEE Seventh International Conference on Global Software Engineering (ICGSE). p. 75-83. 
Ghobadi, S. (2015) What drives knowledge sharing in software development teams: A literature review and classification framework. Information and Management, v. 52, n. 1, p. 82-97.

Govers, C. P. (1996) What and how about quality function deployment (QFD). International Journal of Production Economics, Elsevier, v. 46, p. 575-585.

Hartley, J. (2014) Some thoughts on Likert-type scales, International Journal of Clinical and Health Psychology, v. 14, n. 1, p. 83-86.

Huzita, E. H. M.; Wiese, I. S.; Silva, C. A. da; Tait, T. F. C.; Quinaia, M. A.; Schiavoni, F. L. (2008) Um Conjunto de Soluções para Apoiar o Desenvolvimento Distribuído de Software. In: Simpósio Brasileiro de Engenharia de Software - II Workshop de Desenvolvimento Distribuído de Software, 2008, Campinas. Anais II Workshop de Desenvolvimento Distribuído de Software.

Hsieh, P. J.; Lin, B.; Lin, C. (2009) The construction and application of knowledge navigator model (KNM?): An evaluation of knowledge management maturity. Expert Systems with Applications, Elsevier, v. 36, n. 2, p. 4087-4100.

Ishii, F. T.; Leal, G. C. L.; Galdamez, E. V. C.; Balancieri, R.; Huzita, E. H. M.; Tait, T. F. C. (2013) Knowledge Management in Distributed Software Development: A Systematic Review. In: XIX Congreso Argentino de Ciencias de la Computacion, 2013, Mar del Plata. XIX Congreso Argentino de Ciencias de la Computación CACIC 2013. Mar del Plata: Fundación de Altos Estudios en Ciencias Exactas,. p. 587-866.

Jamieson, S. (2004) Likert scales: how to (ab) use them, Medical Education, v. 38, n. 12, p. 1217-1218.

Kitchenham, B. A.; Pfleeger, S. L. (2008) Personal opinion surveys, Guide to Advanced Empirical Software Engineering, p. 63-92.

Kulkarni, U.; Freeze, R. (2004) Development and validation of a knowledge management capability assessment model. Proceedings of the International Conference on Information Systems (ICIS 2004), Washington, DC, USA, p. 54.

Kuriakose, K. K.; Baldev, R.; Satya Murty, S. A. V.; Swaminathan, P. (2011) Knowledge management maturity model: an engineering. Approach. Journal of Knowledge Management Practice, Tla Inc, v. 12, n. 2.

Landim, P. M. B. (2003) Análise estatística de dados geológicos. 2. ed., Editora UNESP.

Li, Q. (2013) A novel likert scale based on fuzzy sets theory, Expert Systems with Applications, v. 40, n. 5, p. 1609-1618

Lin, H. F. (2007) A stage model of knowledge management: an empirical investigation of process and effectiveness, Journal of Information Science, Sage Publications, v. 32, n. 1, p. 23-39.

LIN, C.; WU, J.-C.; YEN, D. C. (2012) Exploring barriers to knowledge flow at different knowledge management maturity stages. Information and Management, Elsevier, v. 49, n. 1, p. 10. 
Madeyski, L. (2010) The impact of test-rst programming on branch coverage and mutation score indicator of unit tests: An experiment, Information and Software Technology, v. 52, n. 2, p. 169-184.

Massago, Y. (2015) Influência dos Aspectos Socioculturais em um Modelo de Maturidade para Gestão do Conhecimento. Dissertação de Mestrado, PCC-UEM.

Massago, Y.; Leal, G. C. L.; Balancieri, R.; Galdamez, E. V. C. (2018) Towards Classifying Sociocultural Aspects in Global Software Development. Revista de Gestão da Tecnologia e Sistemas de Informação (Online), v. 15, p. 1-19.

Oliveira, M.; Pedron, C. D.; Romão, M.; Becker, G. V. (2011) Proposta de um modelo de maturidade para gestão do conhecimento: KM3, Revista Portuguesa e Brasileira de Gestão, INDEG/PROJECTOS-Instituto para o Desenvolvimento da Gestão Empresarial, v. 10, n. 4, p. 14-25.

Paulk, M. C.; Weber, C. V.; Curtis, B.; Chrissis, M. B. (1995) The capability maturity model: Guidelines for improving the software process, Addison-wesley Reading, MA, p. 441.

Prasad, B. (1998) Review of QFD and related deployment techniques. Journal of manufacturing Systems, Elsevier, v. 17, n. 3, p. 221-234.

Prikladnicki, R.; Lopes, L.; Audy, J. L. N.; Evaristo, R. (2004) Desenvolvimento distribuído de software: um modelo de classificação dos níveis de dispersão dos stakeholders, In: I Brazilian Symposium on Information Systems (SBSI 04). p. 253262.

Shull, F.; Basili, V.; Carver, J.; Maldonado, J. C.; Travassos, G. H.; Mendonça, M.; Fabbri, S. (2002) Replicating software engineering experiments: addressing the tacit knowledge problem, In: IEEE. Proceedings. 2002 International Symposium on Empirical Software Engineering. p. 7-16.

Silva, F. Q.; Costa, C.; Cesar França, A.; Prikladinicki, R. (2010) Challenges and solutions in distributed software development project management: a systematic literature review, In: IEEE. 5th IEEE International Conference on Global Software Engineering (ICGSE). p. 87-96.

Sinha, R. (2013) A comparative analysis of knowledge management process maturity models, International Journal of Innovative Research and Studies, v. 2, n. 5, p. 221234.

Sivasamy, K.; Arumugam, C.; Devadasan, S. R.; Murugesh, R.; Thilak, V. M. M. (2016) Advanced models of quality function deployment: a literature review. Quality and Quantity, v. 50, n. 3, p. 1399-1414.

Sjoberg, D. I.; Dyba, T.; Jorgensen, M. (2007) The future of empirical methods in software engineering research, Future of Software Engineering, FOSE'07 , IEEE, p. $358-378$.

Smite, D.; Moe, N. B.; Sablis, A. Wohlin, C. (2017) Software teams and their knowledge networks in large-scale software development. Information and Software Technology, v. 86, p. 71-86. 
Vivian, R. L.; Huzita, E. H. M.; Leal, G. C. L. (2013) Supporting distributed software development through context awareness on software artifacts: The DISENCollaborar approach, In: Proceedings of the 28th Annual ACM Symposium on Applied Computing. New York, NY, USA: ACM. p. 765-770. 